\title{
The Seagrass Holobiont and Its Microbiome
}

\author{
Kelly Ugarelli, Seemanti Chakrabarti, Peeter Laas and Ulrich Stingl * \\ Ft. Lauderdale Research and Education Center, Department of Microbiology and Cell Science, UF/IFAS, \\ University of Florida, Davie, FL 33314, USA; kugarelli@ufl.edu (K.U.); seemanti@ufl.edu (S.C.); \\ peeter.laas@ufl.edu (P.L.) \\ * Correspondence: ustingl@ufl.edu; Tel: +1-954-577-6326
}

Received: 2 November 2017; Accepted: 5 December 2017; Published: 15 December 2017

\begin{abstract}
Seagrass meadows are ecologically and economically important components of many coastal areas worldwide. Ecosystem services provided by seagrasses include reducing the number of microbial pathogens in the water, providing food, shelter and nurseries for many species, and decreasing the impact of waves on the shorelines. A global assessment reported that $29 \%$ of the known areal extent of seagrasses has disappeared since seagrass areas were initially recorded in 1879. Several factors such as direct and indirect human activity contribute to the demise of seagrasses. One of the main reasons for seagrass die-offs all over the world is increased sulfide concentrations in the sediment that result from the activity of sulfate-reducing prokaryotes, which perform the last step of the anaerobic food chain in marine sediments and reduce sulfate to $\mathrm{H}_{2} \mathrm{~S}$. Recent seagrass die-offs, e.g., in the Florida and Biscayne Bays, were caused by an increase in pore-water sulfide concentrations in the sediment, which were the combined result of unfavorable environmental conditions and the activities of various groups of heterotrophic bacteria in the sulfate-rich water-column and sediment that are stimulated through increased nutrient concentrations. Under normal circumstances, seagrasses are able to withstand low levels of sulfide, probably partly due to microbial symbionts, which detoxify sulfide by oxidizing it to sulfur or sulfate. Novel studies are beginning to give greater insights into the interactions of microbes and seagrasses, not only in the sulfur cycle. Here, we review the literature on the basic ecology and biology of seagrasses and focus on studies describing their microbiome.
\end{abstract}

Keywords: seagrass; microbiome; sulfide; rhizosphere; holobiont

\section{Seagrass Diversity and Ecology}

Seagrasses are descendants of terrestrial plants that colonized the sea on at least three different occasions, starting around 100 million years ago [1,2]. They are aquatic angiosperms that form a coherent ecological group, but are quite diverse in terms of phylogeny [3] containing around 70 species of basal monocots that belong to four or five families (depending on the reference) in the order Alismatales. These families include Hydrocharitaceae, Posidoniaceae, Zosteraceae, Cymodoceaceae, and Ruppiaceae, with the two latter sometimes being considered as one family [1]. The morphology of seagrasses is very similar to other aquatic plants with the exception of the formation of filiform pollen (Zosteraceae, Posidoniaceae, Cymodoceaceae) and strings of spherical pollen (Thalassia, Halophila) [4-6].

\subsection{Distribution}

The total area covered by seagrass meadows is poorly known, but recent estimates range between 300,000 and $600,000 \mathrm{~km}^{2}[7,8]$. All continents except Antarctica harbor seagrass meadows. The water depth to which seagrasses can grow is limited by the amount of light penetrating the water column of marine environments [9]. Depending on the species, seagrasses have been found to grow in a wide range of depths both subtidally and intertidally, ranging from 1 to $3 \mathrm{~m}$ to a maximum of $58 \mathrm{~m}$ [10]. 
The species diversity of seagrass meadows can vary from one dominant species in most of the coastal regions to as many as 14 in the tropics [11].

\subsection{Adaptations to Marine Environments}

Compared to terrestrial plants, seagrasses show adaptations to the marine environment and the concomitant high salinity. For example, Olsen et al. [1] demonstrates the absence of genes involved in stomatal differentiation and synthesis and sensing of volatile compounds in Zostera marina, the only genome-sequenced seagrass species so far, which allows its existence in the ocean. A reduction in the number of defense-related genes in Z. marina has been correlated to the absence of stomata that normally act as an entry point of pathogens and pests [1]. Z. marina has also lost most of its UV resistance genes while the number of light-harvesting complex B genes required for thriving in the low-light conditions of the sea increased [1,12]. To protect their cell walls against desiccation and strong osmotic pressure, seagrasses have regained the ability to produce sulfated polysaccharides, which promote water and ion retention in the cell wall, a feature lost in some terrestrial and freshwater plants [1].

Seagrass cell walls contain all of the typical polysaccharides of land plants, but also contain polyanionic, low-methylated pectins and sulfated galactans, similar to cell walls of most macroalgae. These cell wall constituents are important for ion balancing, nutrient uptake and $\mathrm{O}_{2} / \mathrm{CO}_{2}$ exchange through leaf epidermal cells [1]. Organic osmolytes as well as small cytoplasm:vacuole ratios also help maintain the osmotic equilibrium in marine environments [1,3].

\subsection{Reproduction}

Seagrasses reproduce both asexually and sexually. Their underground connection through a network of root-like structures called rhizomes intermittently give off shoots and lead to clonal growth and asexual reproduction. In sexual reproduction, male flowers produce pollen, which are distributed by the movement of the water or through small invertebrates $[1,6,13,14]$. A microsatellite study by Arnaud-Haround et al. [15] suggested that the sexual mating system of seagrasses is likely based on random large-scale dispersal, an important aspect for the ecology and evolution of seagrass.

\section{Seagrass Ecosystem Services}

Seagrasses are mostly found in shallow marine waters, such as bays and lagoons, where they form vast meadows and fulfill important ecological services [16,17]. With a single acre producing over 10 tons of leaves per year, the dense, leafy canopies of seagrass beds are shelter, food and nursery for numerous animals, including commercially relevant fish and shellfish [18-22]. One acre of seagrass alone can support up to 40,000 fish and 50 million invertebrates [21]. Because of the rich biodiversity in seagrass beds, these meadows are being used as indicators to determine the health of coastal ecosystems [23-26]. Not only do seagrasses provide food and shelter, but they also buffer waves and trap fine sediments and particles suspended in the water column, thus increasing water clarity $[3,27,28]$.

\subsection{Seagrasses and Blue Carbon}

Blue carbon is defined as the carbon acquired by oceans and coastal habitat [29]. Seagrasses play a major role in capturing and holding carbon and thereby act as a carbon sink [30]. They primarily capture carbon dioxide from the atmosphere through photosynthesis and subsequently buildup biomass. Various techniques have been used to determine the carbon pool in coastal ecosystems [31], and it has been estimated that the global seagrass community produces between 20.73 and $101.39 \mathrm{Tg} \mathrm{C}$ per year [25]. It was also reported that seagrass ecosystems accumulate as much as $19.9 \mathrm{Pg}$ of organic carbon [32], which accounts for nearly $15 \%$ of the total global carbon storage [33,34]. As a byproduct of photosynthesis, one square meter of seagrass produces up to ten liters of oxygen per day, thereby constantly oxidizing and recycling key inorganic nutrients and increasing oxygen levels in the water column [35,36]. Consequently, the rise in oxygen levels in seagrass bed leads to a surge in macrophyte, algae and phytoplankton populations [35]. Howard et al. [37] discussed that while considering blue carbon storage, it is important 
to consider the stocks of both organic and inorganic carbon as they both might have an overall effect on the seagrass ecosystem. According to Lovelock et al. [38], 70-80\% of the carbon stocks in the top sediment layer of the coastal wetlands has been lost as carbon dioxide emissions due to disturbance events over the past 40 years. The carbon dioxide emitted by destruction and disturbances of seagrasses as well as mangroves and marshes can cost between $\$ 6-42$ billion annually [39].

\subsection{Seagrasses as Food Source}

Manatees, dugongs, green sea turtles and geese use living seagrass leaves directly as a food source, despite unfavorably high $\mathrm{C}: \mathrm{N}$ ratios and high cellulose levels $[18,36,40]$. Manatees can consume 30-55 kg of seagrass daily [41,42], dugongs can eat between 28 and $40 \mathrm{~kg}$, and sea turtles can eat up to $2 \mathrm{~kg}$ of seagrass per day [36]. Crustaceans and snails also occasionally consume seagrass leaves [36].

Many of the species that inhabit seagrass meadows tend to be carnivorous and feed on animals that live within the seagrass beds and other organisms that frequent the meadows [18,40]. Bacteria living epiphytically on the seagrass leaves provide a source of food for invertebrates such as crustaceans and snails, which in turn decrease the amount of debris in the seagrass meadows. Mucous released by these organisms can however coat seagrass leaves and obstruct sunlight [36]. Regularly, bacterial decomposition of dead seagrass plants provides detritus as food for worms, sea cucumbers, crabs, and filter feeders such as anemones and ascidians. Additionally, seagrass detritus and debris can be carried to the shore as well as to the deep sea, where they are available as food source for organisms farther away from the seagrass beds [36]. Further decomposition releases nutrients, such as nitrogen and phosphorus, which are reabsorbed by seagrasses and phytoplankton [40].

\subsection{Seagrasses as Habitat and Nursery}

Seagrasses serve as a keystone habitat for migrating coral reef species as well as thousands of other animals, including water birds and other frequent visitors. The sediments in seagrass meadows are mainly inhabited by invertebrate species consisting of echinoderms, crustaceans (including copepods, amphipods and ostracods), bivalves, polychaetes and nematodes in adult and immature stages [18-20]. Other animals living in the water above and within the seagrass beds include fish, shrimps, prawns, amphipods and isopods [18]. Seagrasses are also commonly used as nurseries by several fish including pollock, cod, herring and whiting [18-20].

\subsection{Seagrasses Reduce the Number of Pathogens}

In addition to providing shelter and food, seagrass ecosystems can reduce exposure to bacterial pathogens of fishes, invertebrates and humans. In the presence of seagrass meadows, a $50 \%$ reduction in the relative abundances of bacterial populations known to cause diseases both in humans and marine organisms, was observed [43]. An in vitro study by Kannan et al. [44] showed that phytochemicals isolated from seagrass tissues can kill or inhibit numerous bacterial pathogens. In general, seagrasses are effective at reducing the bacterial loads, which could benefit several organisms [44].

\subsection{Seagrasses as Ecosystem Engineers}

Seagrass meadows are important for the protection and stability of shorelines. Together with coral reefs and mangroves, seagrasses provide a barrier against the harsh waves commonly generated by storms and also help to prevent the loss of sediment [17]. Seagrass roots extend both vertically and horizontally, preventing the plant from being uprooted and providing shallow coastal areas with additional protection from erosion caused to strong wave and tide energy. Seagrasses can reduce wave and bed shear stresses nearshore by more than $60 \%$ [17]. A study by de los Santos et al. [45] examined the ability of seagrass species to withstand forces that mimic the strength of waves and currents. The study focused on the leaves of 22 species, concluding that temperate seagrasses are more capable of resisting breakage than tropical species because of constant exposure to harsher physical conditions [45]. Additionally, seagrasses play an important role in defining coastal areas, supplying 
biogenic detritus made of seagrass roots and debris, mollusks, echinoids, algae, foraminifera and bivalve fragments, all of which are species that reside within the meadows [46,47]. This deposited biogenic debris leads to calcareous, shelly beaches and sand flats or dunes commonly occurring in temperate regions such as southern and southwestern Australia [46,47]. In the Mediterranean Sea, meadows of Posidonia oceanica are the main carbonate source for the beaches and coastal systems, producing high levels of carbonate from its inhabitants [46].

When a seafloor area lacks seagrass communities, the sediments are more frequently stirred up by wind and waves [40]. A study by Moore [35] revealed that in the presence of ample amounts of seagrass during spring and early summer, the level of total suspended solids (TSS) in the water column was much lower than in unvegetated areas. During midsummer to fall, when seagrasses become less abundant, sediment and other materials resuspend and increase the levels of TSS [35]. As a result, water clarity decreases, affecting marine animal behavior and generally decreasing the recreational quality of coastal areas [40]. Seagrasses also trap and filter nutrients that come from land-based industrial discharge and stormwater runoff before these nutrients are washed out to sea where they can have detrimental effects on other sensitive habitats such as coral reefs [36,40]. Furthermore, seagrass meadows release parts of the nutrients they absorb from the sediment back into the water, incidentally supplying the surrounding environment with nutrients [36].

\section{Seagrasses under Threat}

Losses of seagrass habitats have been observed worldwide. Waycott et al. [28] estimated that nearly $29 \%$ of the global area covered by seagrasses has already disappeared since 1879 , meaning that also the ecosystem services provided by seagrasses decreased by about one third. In Southeast Asia, a loss of up to $40 \%$ of the seagrass meadows has been reported [48-50], and in the Mediterranean about $30 \%$ has been lost [51]. The loss of seagrass beds could potentially cause large amounts of carbon dioxide emissions, contributing as much as $10 \%$ of the $0.5-2.7 \mathrm{Gt} \mathrm{C}$ per year released from changes in land use [32]. Several major die-offs have occurred in the past, for instance in the 1930s, 1980s and, more recently, in 2015 with turtle grass as the main species affected, although other species have also suffered [28,52-56]. Table 1 provides a list of different regions and the seagrass species affected.

Table 1. List of seagrass species affected by die-off events in different regions of the world.

\begin{tabular}{|c|c|c|}
\hline Region & Species Affected & References \\
\hline Asia & $\begin{array}{l}\text { Cymodocea rotundata, Enhalus acoroides, } \\
\text { Halodule pinifolia, Halodule uninervis, } \\
\text { Halophila beccarii, Halophila decipiens, } \\
\text { Halophila ovalis, Ruppia maritima, Thalassia } \\
\text { hemprichi, Zostera asiatica, Zostera japonica, } \\
\text { Zostera marina }\end{array}$ & $\begin{array}{l}\text { Unsworth et al., } 2016 \text { [48], Tomascik et al., } 1997 \text { [49], } \\
\text { Nadiarti et al., } 2012 \text { [50], Short and Green } 2003 \text { [59], } \\
\text { Halun et al., } 2002 \text { [64], Terrados et al., } 1998 \text { [65], } \\
\text { Japar et al., } 1995 \text { [66], Japar et al., } 1999 \text { [67], } \\
\text { Japar et al., 2001 [68], Mukai et al., } 1999 \text { [69], Parthasarathy } \\
\text { et al., } 1988 \text { [70], Parthasarathy et al., } 1991 \text { [71], } \\
\text { Short et al., } 2011 \text { [72] }\end{array}$ \\
\hline Australia & $\begin{array}{l}\text { Amphibolis antarctica Halophila ovalis, } \\
\text { Posidonia angustifolia, Posidonia australis, } \\
\text { Posidonia sinuosa, Ruppia megacarpa, Zostera } \\
\text { capricorni, Zostera muelleri, Zostera tasmanica }\end{array}$ & $\begin{array}{l}\text { Walker and McComb } 1992 \text { [73], Short and Green } 2003 \text { [59], } \\
\text { Dennison and Abal } 1999 \text { [74], Larkum and West } 1990 \text { [75], } \\
\text { Kirkman and Kendrick 1997 [76], Wells et al., } 1991 \text { [77], } \\
\text { Silberstein et al., 1986 [78], Cambridge et al., } 1986 \text { [79], } \\
\text { Short et al., } 2011 \text { [72] }\end{array}$ \\
\hline North America & $\begin{array}{l}\text { Halodule wrightii, Halophila engelmannii, } \\
\text { Ruppia maritima, Syringodium filiforme, } \\
\text { Thalassia testudinum, Zostera marina }\end{array}$ & $\begin{array}{l}\text { Zieman et al., } 1999 \text { [53], Orth and Moore 1983 [52], } \\
\text { Waycott et al., } 2009 \text { [28], Hall et al., } 1999 \text { [80], } \\
\text { Borum et al., } 2005 \text { [81], Thayer et al., } 1984 \text { [82], } \\
\text { Short et al., } 1996 \text { [83], Wyllie-Echeverria et al., } 1999 \text { [84], } \\
\text { Lathrop et al., } 2001 \text { [85], Renn } 1934 \text { [86], Tutin } 1938 \text { [87], } \\
\text { Sargent et al., } 1995 \text { [88], Hall et al., 1999 [80], } \\
\text { Eleuterius 1973 [89], Sullivan 1979 [90], } \\
\text { Short et al., } 2002 \text { [91], Hauxwell et al., } 2001 \text { [92] }\end{array}$ \\
\hline
\end{tabular}


Table 1. Cont.

\begin{tabular}{cll}
\hline Region & \multicolumn{1}{c}{ Species Affected } & \multicolumn{1}{c}{ References } \\
\hline \multirow{2}{*}{ South America } & Halodule wrightii, Ruppia maritima & $\begin{array}{l}\text { Short and Green 2003 [59], Phillips 1992 [93], } \\
\text { Seeliger et al., 1997 [94], Oliveira et al., 1983 [95] }\end{array}$ \\
\hline \multirow{3}{*}{ Europe } & Cymodocea nodosa, Posidonia oceanica, Zostera & Short and Green 2003 [59], Blegvad 1935 [96], \\
& marina, Zostera noltii & Belcon 1998 [97], Rasmussen 1973 [98], \\
& & Whelan and Cullinane 1987 [101], de Jonge and de Jonge \\
& 1992 [102], Frederiksen et al., 2004 [103], \\
\end{tabular}

\subsection{Human Activity}

The major cause for the loss of seagrass is human activity. Beach erosion and deposition of fine sediments partly disturb and alter seagrass beds. For instance, $P$. oceanica disappeared due to siltation caused by the building of embankments in Italy, while another seagrass species, Cymodocea nodosa, began to appear $[105,106]$. Not only does siltation alter seagrass meadows, but it also decreases seagrass health by blocking sunlight due to the increase of particles in the water column, as well as by altering sediment composition [64,105]. Human activities such as coastal development, damming, and waste disposal into the ocean also impact the health of seagrasses and hinder their ability to provide ecosystem services, which can contribute to global warming due to the loss of a carbon sink $[18,107,108]$. The rising temperatures of the ocean in turn distress seagrass meadows causing reduced shoot lengths, which lead to other complications such as lack of exposure to light [109].

One of the most destructive human activities is the eutrophication of coastal waters. Eutrophication is due to effluence of nutrients and coastal development, leading to increased nutrient concentrations in the sea that promote the growth of epiphytes such as algae, which negatively affect seagrasses by blocking sunlight $[73,108,110-113]$. The most common substances leaked into the ocean include nitrogen and phosphorous compounds [113], but other chemicals found in groundwater, such as radon and methane, also often seep into the ocean [114]. Other less destructive human activities include fishing and collecting mollusks and crustaceans $[18,107,108]$.

\subsection{Sulfide}

Sulfide is highly toxic for animals and plants, and has been described as a major contributor to seagrass die-offs all over the world [3,59]. It is detrimental to several plant biological processes, such as photosynthesis, and is thought to be trapped in great amounts in the sediment of seagrass beds, where there is less iron available to sequester the sulfide [81]. Some species of seagrasses are more resistant to higher sulfide concentrations due to lesser biomass below the sediment, whereas turtle grass e.g., is less resistant [80]. Most marine and estuarine sediments are rich in sulfide due to activities of sulfate-reducing prokaryotes that perform the last step of the anaerobic food chain by oxidizing organic carbon and simultaneously reducing sulfate to $\mathrm{H}_{2} \mathrm{~S}$ [115]. Several studies suggest that die-offs in the Florida and Biscayne Bays are caused by an increase in sulfide concentrations as a result of unfavorable environmental conditions and the activities of many different groups of heterotrophic bacteria in the sulfate-rich water-column and sediment $[64,80]$. For instance, a recent drought in 2015 lead to increased sulfide concentrations in the ocean, raising its toxicity and causing major losses of seagrass beds in the Florida Bay [55].

Low oxygen levels in the sediment lead to the uptake of toxic sulfide into the shoots $[81,116,117]$. Nonetheless, under normal conditions, seagrasses are able to withstand low levels of sulfide, probably partly due to microbial symbionts that detoxify sulfide by oxidizing it to sulfur or sulfate. However, an increase in sulfide concentrations has been shown to reduce shoot, rhizome and root production, eventually resulting in mass mortality of seagrasses [64]. 


\subsection{Other Natural Threats}

Other natural causes of seagrass depletion include competition among species of seagrasses and seaweeds for habitat and resources $[56,118,119]$, as well as diseases e.g., caused by the protozoan Labyrinthula $[59,80,91,120,121]$. Overgrazing by herbivores such as sea urchins can also contribute to the decaying seagrass population [122]. Furthermore, severe weather conditions, including hurricanes, can thin seagrass beds and deposit and erode sediments, thus altering the composition of both the water column and sediment which causes further deterioration of the seagrasses [123]. In general, factors that have a negative effect on seagrasses also negatively impact their microbial community, and damage the general health of seagrass meadows [124].

\section{The Seagrass Holobiont}

The concept of the holobiont [125], which emphasizes the importance and interactions of a microbial host with associated microorganisms and viruses and describes their functioning as a single biological unit, has been investigated and discussed for many model systems, although there is substantial criticism on a concept that defines diverse host-microbe symbioses as a single biological unit [126]. The holobiont and hologenome concepts have evolved since the original definition [127] and there is no doubt that symbiotic microorganisms are pivotal for the biology and ecology of the host by providing vitamins, energy and inorganic or organic nutrients, participating in defense mechanisms, or by driving the evolution of the host [128]. Although most work on host-microbe interactions has been focused on animal systems such as corals [129], sponges [130], or humans [131], there is a substantial body of literature on plant holobionts [132]. Plant-associated microbial communities impact both key components of the fitness of plants, growth and survival [133], and are shaped by nutrient availability and plant defense mechanisms [134]. Several habitats have been described to harbor plant-associated microbes, including the rhizoplane (surface of root tissue), the rhizosphere (periphery of the roots), the endosphere (inside plant tissue), and the phyllosphere (total above-ground surface area). In the following paragraphs, we review the existing literature on associations of seagrasses with microorganisms and discuss potential functional aspects of microorganisms that can impact growth and fitness of seagrasses.

\section{Functions and Interactions of Seagrass Microbiome}

Our knowledge of the seagrass holobiont has only recently started to take shape. Technological limitations and divergent sampling methods conducted in limited numbers of geographical areas and host species, along with a focus on specific members of the microbial communities instead of the total microbiome, lead to numerous individual results yet an incomplete understanding of the structure and function of the holobiont (Table 2). The literature on epiphytic algae and invertebrates has been summarized in detail elsewhere [135]; thus, this review focuses on the microbiome. The latest review on the seagrass rhizosphere communities was published more than ten years ago [136]. Metabolic capabilities and phylogenetic composition of microbial communities are unquestionably linked; however, most of the studies presented here have addressed either the structural or functional aspects of the microbiome. Earlier investigations have provided overwhelming evidence of direct links between the activities of seagrass hosts and their microbiomes (Figure 1). For clarity, these activities are discussed in relation to different biogeochemical cycles and protective functions. 
Table 2. Detailed overview on studies on the microbiome of seagrasses.

\begin{tabular}{|c|c|c|c|c|c|c|c|}
\hline $\begin{array}{l}\text { Structure, Function, } \\
\text { or both }(\mathrm{S}, \mathrm{F}, \mathrm{B})\end{array}$ & Reference & Study Area & Methodology & Seagrass Species & Target & $\begin{array}{c}\text { Compartment } \\
\text { of Microbiome }\end{array}$ & Main Results \\
\hline B & Agawin et al., 2016 [137] & $\begin{array}{l}\text { Alcudia Bay, } \\
\text { Mallorca, Spain }\end{array}$ & $\begin{array}{l}\text { Sanger sequencing of } \\
\text { nifH genes, acetylene } \\
\text { reduction assay }\end{array}$ & Posidonia oceanica & $\mathrm{N}$-fixing bacteria & Phyllosphere & $\begin{array}{l}\text { Identified significant nitrogen } \\
\text { fixation activity in phyllosphere. }\end{array}$ \\
\hline B & Bagwell et al., 2002 [138] & Eastern Bahamas & $\begin{array}{l}\text { DGGE to resolve } \\
\text { PCR-amplified nifH } \\
\text { sequences }\end{array}$ & $\begin{array}{l}\text { Thalassia } \\
\text { testudinum }\end{array}$ & $\mathrm{N}$-fixing bacteria & Rhizosphere & $\begin{array}{l}\text { Identified diverse diazotroph } \\
\text { assemblages in the rhizosphere and } \\
\text { found similarities to communities } \\
\text { associated with an intertidal } \\
\text { grass (Spartina alterniflora). }\end{array}$ \\
\hline B & Kurilenko et al., 2010 [139] & $\begin{array}{l}\text { Troitza Bay, Gulf of } \\
\text { Peter the Great, } \\
\text { Pacific Ocean }\end{array}$ & Cultivation & Zostera marina & $\begin{array}{l}\text { Granulosicoccus } \\
\text { coccoides }\end{array}$ & Phyllosphere & Described a new bacterial species. \\
\hline B & Küsel et al., 1999 [140] & $\begin{array}{l}\text { Santa Rosa Sound, } \\
\text { Florida, USA }\end{array}$ & $\begin{array}{c}\text { Phospholipid fatty } \\
\text { acid analysis, } \\
\text { cultivation, } \\
\text { oligonucleotide probes }\end{array}$ & $\begin{array}{l}\text { Halodule wrightii, } \\
\text { Thalassia testudinum }\end{array}$ & Archaea, Bacteria & $\begin{array}{l}\text { Endosphere, } \\
\text { rhizosphere }\end{array}$ & $\begin{array}{l}\text { Acetogenic bacteria were dominant } \\
\text { on rhizoplane, and sulfate reducers } \\
\text { in the endosphere. }\end{array}$ \\
\hline B & Marhaeni et al., 2010 [141] & Central Java, Indonesia & $\begin{array}{l}\text { Cultivation and } \\
\text { antifouling test via } \\
\text { agar diffusion method }\end{array}$ & Enhalus sp. & Bacteria & $\begin{array}{l}\text { Endosphere, } \\
\text { phyllosphere, } \\
\text { rhizosphere }\end{array}$ & $\begin{array}{c}\text { Identified epiphytic and endophytic } \\
\text { bacteria that potentially act as } \\
\text { natural antifoulants. }\end{array}$ \\
\hline B & Newell et al., 1981 [142] & Chesapeake Bay, USA & Cultivation & Zostera marina & Fungi and Bacteria & Phyllosphere & $\begin{array}{l}\text { Fungal biomass did not account for } \\
\text { more than } 0.5 \% \text { of leaf mass; } \\
\text { estimated bacterial productivity } 1.4 \times \\
\text { standing stock per day. }\end{array}$ \\
\hline B & Nielsen et al., 2001 [143] & Bay of Arcachon, France & $\begin{array}{l}\text { Sulfate and acetylene } \\
\text { reduction rate } \\
\text { measurements, } \\
\text { scanning electron } \\
\text { microscopy, cultivation }\end{array}$ & Zostera noltii & $\begin{array}{l}\text { Sulfate reducing } \\
\text { and } N \text {-fixing } \\
\text { microorganisms }\end{array}$ & Rhizosphere & $\begin{array}{l}\text { Observed patchy distribution of } \\
\text { bacteria on the roots and rhizomes. } \\
\text { Addition of sucrose stimulated } \\
N \text {-fixation and sulfate reduction } \\
\text { significantly in the rhizosphere, but } \\
\text { not in the bulk sediment. }\end{array}$ \\
\hline $\mathrm{F}$ & $\begin{array}{c}\text { Blaabjerg and } \\
\text { Finster, } 1998 \text { [144] }\end{array}$ & Limfjorden, Denmark & $\begin{array}{l}\text { Sulfate reduction } \\
\text { rates using } \\
\text { radiolabeled sulfate }\end{array}$ & Zostera marina & Sulfate reducers & $\begin{array}{l}\text { Endosphere, } \\
\text { rhizosphere }\end{array}$ & $\begin{array}{c}\text { Demonstrated that root } \\
\text { surface-associated sulfate reducers } \\
\text { have high tolerance towards oxygen. }\end{array}$ \\
\hline $\mathrm{F}$ & Blaabjerg et al., 1998 [145] & Limfjorden, Denmark & $\begin{array}{l}\text { Sulfate reduction } \\
\text { rates using } \\
\text { radiolabeled sulfate }\end{array}$ & Zostera marina & Sulfate reducers & Rhizosphere & $\begin{array}{l}\text { Sulfate reduction rates were } 3 \text { times } \\
\text { higher in August than in April, and } \\
\text { were significantly positively } \\
\text { correlated to light intensity. }\end{array}$ \\
\hline $\mathrm{F}$ & Boon et al., 1986 [146] & Moreton Bay, Australia & $15 \mathrm{~N}$ isotope technique & Zostera capricorni & $\begin{array}{l}\text { Ammonium turnover, } \\
\text { glycine utilization }\end{array}$ & Rhizosphere & $\begin{array}{l}\text { Greater ammonification rates in } \\
\text { rhizosphere than in adjacent } \\
\text { bare sediments. }\end{array}$ \\
\hline
\end{tabular}


Table 2. Cont

\begin{tabular}{|c|c|c|c|c|c|c|c|}
\hline F & Boschker et al., 2000 [147] & Northwest Europe & $\begin{array}{l}\text { Stable carbon-isotope } \\
\text { ratios of bacteria, } \\
\text { sediment organic } \\
\text { matter and plants }\end{array}$ & $\begin{array}{l}\text { Zostera marina and } \\
\text { Z. noltii }\end{array}$ & $\begin{array}{l}\text { Biogeochemistry } \\
\text { of rhizosphere }\end{array}$ & Rhizosphere & $\begin{array}{l}\text { Seagrass material was of limited } \\
\text { importance as a bacterial } \\
\text { carbon source. }\end{array}$ \\
\hline $\mathrm{F}$ & $\begin{array}{l}\text { Caffrey and Kemp } \\
1990[148]\end{array}$ & Choptank River, USA & $\begin{array}{l}\text { Rates of nitrification, } \\
\text { denitrification and } \\
\text { ammonification }\end{array}$ & Zostera marina & Nitrogen cycling & Rhizosphere & $\begin{array}{l}\text { Microbial communities are } \\
\text { responsible for key nitrogen } \\
\text { transformations in the rhizospheres } \\
\text { of Z. marina and P. portfeliatus. }\end{array}$ \\
\hline $\mathrm{F}$ & $\begin{array}{c}\text { Capone and Taylor } \\
1980 \text { [149] }\end{array}$ & $\begin{array}{l}\text { Biscayne Bay, USA, and } \\
\text { Bimini Harbor, Bahamas }\end{array}$ & $\begin{array}{l}\text { Nitrogen fixation } \\
\text { rates, acetylene } \\
\text { reduction assay }\end{array}$ & $\begin{array}{l}\text { Thalassia } \\
\text { testudinum }\end{array}$ & $N$-fixing bacteria & Rhizosphere & $\begin{array}{l}\text { Rates of } N \text {-fixation were } 20 \text {-fold } \\
\text { higher in the summer compared to } \\
\text { winter. } 10^{\circ} \mathrm{C} \text { drop in temperature } \\
\text { halved } N \text {-fixation rates. }\end{array}$ \\
\hline $\mathrm{F}$ & $\begin{array}{l}\text { Frederiksen and Glud } \\
2006[150]\end{array}$ & Svenstrup, Denmark & $\begin{array}{c}\text { Planar } \mathrm{O}_{2} \\
\text { measurements }\end{array}$ & Zostera marina & Oxygen dynamics & Rhizosphere & $\begin{array}{l}\text { Rhizospheres of seagrass are } \\
\text { probably of minor importance for } \\
\text { total benthic } \mathrm{O}_{2} \text { uptake rates. }\end{array}$ \\
\hline $\mathrm{F}$ & Holmer et al., 2001 [151] & Phuket Island, Thailand & $\begin{array}{l}\text { Sulfate reduction rates; } \\
\text { stable carbon isotope } \\
\text { composition of } \\
\text { seagrasses, sediments } \\
\text { and bacteria }\end{array}$ & $\begin{array}{c}\text { Cymodocea } \\
\text { rotundata, Thalassia } \\
\text { hemprichii }\end{array}$ & $\begin{array}{l}\text { Carbon cycling, } \\
\text { sulfate reducers }\end{array}$ & Rhizosphere & $\begin{array}{l}\text { Determined that bacteria used } \\
\text { organic matter derived from } \\
\text { seagrasses and showed that the } \\
\text { contribution of sulfate reduction to } \\
\text { nutrient availability was low. }\end{array}$ \\
\hline $\mathrm{F}$ & Holmer et al., 2004 [152] & $\begin{array}{l}\text { Mallorca and Cabrera } \\
\text { Islands, Spain }\end{array}$ & $\begin{array}{l}\text { Stable carbon-isotope } \\
\text { ratios of bacterial } \\
\text { phospholipid derived } \\
\text { fatty acids and sulfate } \\
\text { reduction rates with } \\
\text { 1-step distillation }\end{array}$ & $\begin{array}{l}\text { Posidonia oceanica, } \\
\text { Cymodocea nodosa }\end{array}$ & Carbon cycling & Rhizosphere & $\begin{array}{c}\text { Seagrass detritus was a major } \\
\text { bacterial carbon source, but its } \\
\text { importance was decreased in areas } \\
\text { with higher external nutrient loading. }\end{array}$ \\
\hline $\mathrm{F}$ & $\begin{array}{l}\text { Isaksen and Finster, } \\
1996 \text { [153] }\end{array}$ & Bay of Arcachon, France & $\begin{array}{l}\text { Sulfate reduction } \\
\text { rates using } \\
\text { radiotracer method }\end{array}$ & Zostera noltii & Sulfate reducers & Rhizosphere & $\begin{array}{l}\text { Rates of sulfate reduction were twice } \\
\text { as high in rhizosphere as in } \\
\text { equivalent layer of the } \\
\text { unvegetated sediment. }\end{array}$ \\
\hline $\mathrm{F}$ & Jones et al., 2003 [154] & $\begin{array}{l}\text { Lower Laguna } \\
\text { Madre, USA }\end{array}$ & $\begin{array}{l}\text { Stable carbon isotope } \\
\text { ratios in phospholipid } \\
\text { fatty acids }\end{array}$ & $\begin{array}{l}\text { Thalassia } \\
\text { testudinum }\end{array}$ & Bacteria & Rhizosphere & $\begin{array}{l}\text { Majority of sedimentary organic } \\
\text { carbon originated from seagrass } \\
\text { plants and provided important } \\
\text { carbon source for bacteria. }\end{array}$ \\
\hline $\mathrm{F}$ & Kim et al., 2017 [155] & Southern coast of Korea & $\begin{array}{l}\text { Sulfate reduction rates } \\
\text { and turnover of } \\
\text { acid-volatile sulfur }\end{array}$ & $\begin{array}{l}\text { Halophila nipponica, } \\
\text { Zostera marina }\end{array}$ & Sulfur cycling & Rhizosphere & $\begin{array}{l}\text { Sulfate reduction was more } \\
\text { stimulated by the dissolved organic } \\
\text { carbon exuded from the roots of } H \text {. } \\
\text { nipponica compared to those at the } \\
\text { roots of } Z \text {. marina. }\end{array}$ \\
\hline $\mathrm{F}$ & Kirchman et al., 1984 [156] & Great Harbor, USA & $\begin{array}{c}\text { Thymidine } \\
\text { incorporation } \\
\text { (bacterial production) }\end{array}$ & Zostera marina & Bacteria & Phyllosphere & $\begin{array}{l}\text { Heterotrophic bacterial community } \\
\text { of the phyllosphere is almost entirely } \\
\text { supported by their seagrass host. }\end{array}$ \\
\hline
\end{tabular}


Table 2. Cont.

\begin{tabular}{|c|c|c|c|c|c|c|c|}
\hline $\mathrm{F}$ & Koepfler et al., 1993 [157] & $\begin{array}{l}\text { Laguna Madre and } \\
\text { Baffin Bay, USA }\end{array}$ & $\begin{array}{l}\text { Pore-water dissolved } \\
\text { organic carbon } \\
\text { concentrations }\end{array}$ & Halodule wrightii & Carbon cycling & Rhizosphere & $\begin{array}{l}\text { In vegetated sediments, pore-water } \\
\text { dissolved organic carbon } \\
\text { concentrations were } 25 \% \text { higher and } \\
\text { bacterial production rates were } \\
4 \text {-times higher compared to } \\
\text { unvegetated bare sediments }\end{array}$ \\
\hline $\mathrm{F}$ & $\begin{array}{l}\text { Lee and Dunton, } \\
2000[158]\end{array}$ & $\begin{array}{l}\text { Corpus Christi Bay and } \\
\text { Laguna Madre, USA }\end{array}$ & $\begin{array}{l}\text { Photosynthetically } \\
\text { active radiation (PAR) } \\
\text { collected with } \\
\text { spherical quantum } \\
\text { sensor and sulfide } \\
\text { determined according } \\
\text { to Cline (1969) }\end{array}$ & $\begin{array}{l}\text { Thalassia } \\
\text { testudinum }\end{array}$ & $\begin{array}{l}\text { Biogeochemistry } \\
\text { of rhizosphere }\end{array}$ & Rhizosphere & $\begin{array}{l}\text { Determined diurnal dynamics of } \\
\text { sulfide concentrations in pore water } \\
\text { because of photosynthetically } \\
\text { produced oxygen being transported } \\
\text { to below-ground seagrass tissues. }\end{array}$ \\
\hline $\mathrm{F}$ & López et al., 1995 [159] & $\begin{array}{l}\text { Mediterranean } \\
\text { Sea, Spain }\end{array}$ & $\begin{array}{l}\text { Ammonification rates; } \\
\text { exoproteolytic and } \\
\text { exoglucosidase activity }\end{array}$ & Posidonia oceanica & Bacteria & Rhizosphere & $\begin{array}{l}\text { Benthic bacterial activity is directly } \\
\text { related to seagrass productivity. }\end{array}$ \\
\hline $\mathrm{F}$ & $\begin{array}{l}\text { McGlathery et al., } \\
1998 \text { [160] }\end{array}$ & Limfjord, Denmark & $\begin{array}{l}\text { Perfusion technique } \\
\text { (acetylene reduction) }\end{array}$ & Zostera marina & $N$-fixing bacteria & Rhizosphere & $\begin{array}{l}\text { Nitrogen fixation activity was about } \\
\text { 3-times higher in vegetated than } \\
\text { unvegetated sediments. }\end{array}$ \\
\hline $\mathrm{F}$ & Moriarty et al., 1985 [161] & Pelican Banks, Australia & $\begin{array}{c}\text { Thymidine } \\
\text { incorporation and } \\
\text { phospholipid method } \\
\text { for bacterial } \\
\text { production; Sulfate } \\
\text { reduction and methane } \\
\text { production rates }\end{array}$ & Zostera capricorni & Bacteria & Rhizosphere & $\begin{array}{l}\text { Spatial variability overwhelmed } \\
\text { seasonal variability in case of } \\
\text { seagrass productivity and bacterial } \\
\text { productivity; strictly } \\
\text { anaerobic bacteria. }\end{array}$ \\
\hline $\mathrm{F}$ & Moriarty et al., 1986 [162] & $\begin{array}{l}\text { Northern Gulf of } \\
\text { Mexico, USA }\end{array}$ & $\begin{array}{c}\text { Stable isotope } \\
\text { labeling experiments }\end{array}$ & Halodule wrightii & Carbon cycling & $\begin{array}{l}\text { Phyllosphere, } \\
\text { rhizosphere }\end{array}$ & $\begin{array}{l}\text { On average } 11 \% \text { of the fixed carbon } \\
\text { was exuded into the sediments and } \\
1 \% \text { into the water column. It took } 6 \mathrm{~h} \\
\text { for the fixed carbon to be } \\
\text { translocated from leaves to roots. }\end{array}$ \\
\hline $\mathrm{F}$ & $\begin{array}{l}\text { Oremland and } \\
\text { Taylor } 1977 \text { [163] }\end{array}$ & $\begin{array}{l}\text { Caesar Creek, USA, and } \\
\text { Bimini Harbor, Bahamas }\end{array}$ & $\begin{array}{l}\text { Chemical analyses of } \\
\text { gas bubbles }\end{array}$ & $\begin{array}{l}\text { Thalassia } \\
\text { testudinum }\end{array}$ & $\begin{array}{l}\text { Biogeochemistry } \\
\text { of rhizosphere }\end{array}$ & Rhizosphere & $\begin{array}{c}\text { Observed } \mathrm{O}_{2} \text { transport via rhizomes } \\
\text { to sediments and diurnal fluctuation } \\
\text { of this process due photosynthetic } \\
\text { activity of the seagrasses. }\end{array}$ \\
\hline $\mathrm{F}$ & $\begin{array}{l}\text { Patriquin and } \\
\text { Knowles } 1972[164]\end{array}$ & $\begin{array}{l}\text { Clam Cove, } \\
\text { Dear Island, Canada }\end{array}$ & $\begin{array}{l}\text { Cultivation } \\
\text { and acetylene } \\
\text { reduction assay }\end{array}$ & $\begin{array}{l}\text { Thalassia testudinum, } \\
\text { Zostera marina }\end{array}$ & $\mathrm{N}$-fixing bacteria & Rhizosphere & $\begin{array}{l}\text { Estimate that } N \text {-fixing microbes in } \\
\text { the rhizosphere can fully support } \\
\text { nitrogen requirements of the seagrass } \\
\text { host and that their abundance is } \\
50-300 \text { times higher than in } \\
\text { unvegetated sediments. }\end{array}$ \\
\hline $\mathrm{F}$ & $\begin{array}{l}\text { Penhale and } \\
\text { Smith } 1977 \text { [165] }\end{array}$ & Newport River estuary & $\begin{array}{l}\text { Release of DOC using } \\
\text { radiocarbon techniques }\end{array}$ & Zostera marina & Carbon cycling & $\begin{array}{l}\text { Phyllosphere, } \\
\text { rhizosphere }\end{array}$ & $\begin{array}{l}\text { Excretion rates in the dark were } \\
\text { much lower than in the light. }\end{array}$ \\
\hline
\end{tabular}


Table 2. Cont.

\begin{tabular}{|c|c|c|c|c|c|c|c|}
\hline $\mathrm{F}$ & $\begin{array}{l}\text { Sand-Jensen et al., } \\
2005 \text { [166] }\end{array}$ & Roskilde Fjord, Denmark & $\mathrm{O}_{2}$ microelectrodes & Zostera marina & Oxygen dynamics & Rhizosphere & $\begin{array}{l}\text { Determined diurnal dynamics of } \\
\text { oxygen concentrations in } \\
\text { the rhizosphere. }\end{array}$ \\
\hline $\mathrm{F}$ & Smith et al., 1984a [167] & $\begin{array}{l}\text { Back and Bogue } \\
\text { Sounds, USA }\end{array}$ & $\begin{array}{c}\text { Total net } \\
\text { ammonification } \\
\text { by rhizoplane } \\
\text { microflora, cultivation }\end{array}$ & $\begin{array}{l}\text { Zostera marina, } \\
\text { Halodule wrightii }\end{array}$ & $\begin{array}{c}\text { Rhizoplane } \\
\text { bacteria }\end{array}$ & Rhizosphere & $\begin{array}{l}\text { Rates of ammonification were } \\
\text { inversely related to the active growth } \\
\text { season of these seagrasses. }\end{array}$ \\
\hline $\mathrm{F}$ & Smith et al., 1984b [168] & $\begin{array}{c}\text { Great Harbor at Woods } \\
\text { Hole, USA }\end{array}$ & $\begin{array}{l}\text { Polarographic } \\
\text { two-chambered } \\
\text { apparatus fitted with } \\
\mathrm{O}_{2} \text { electrodes }\end{array}$ & Zostera marina & Oxygen dynamics & Rhizosphere & $\begin{array}{l}\mathrm{O}_{2} \text { transport to the root-rhizome } \\
\text { system supported aerobic } \\
\text { root respiration. }\end{array}$ \\
\hline F & $\begin{array}{c}\text { Törnblom and } \\
\text { Søndergaard, } 1999 \text { [169] }\end{array}$ & Roskilde Fjord, Denmark & $\begin{array}{l}\text { Leucine and } \\
\text { thymidine } \\
\text { incorporation } \\
\text { (bacterial production) }\end{array}$ & Zostera marina & Bacteria & Phyllosphere & $\begin{array}{l}\text { Observed a strong correlation } \\
\text { between bacterial production (leaf } \\
\text { attached communities) and host's } \\
\text { primary production. Biomass } \\
\text { production of microbiome was very } \\
\text { high compared to the standing } \\
\text { stock of bacteria. }\end{array}$ \\
\hline $\mathrm{F}$ & Welsh et al., 1996 [170] & $\begin{array}{c}\text { Bassin } \\
\text { d'Arcachon, France }^{2}\end{array}$ & $\begin{array}{l}\text { Acetylene reduction } \\
\text { and cultivation }\end{array}$ & Zostera noltii & $N$-fixing bacteria & Rhizosphere & $\begin{array}{l}\text { Acetylene reduction rates up to } \\
\text { 4-fold greater in the light compared } \\
\text { with those measured in the dark. } \\
\text { Sulfate-reducing bacteria were the } \\
\text { dominant component of the } \\
\text { nitrogen-fixing microflora. }\end{array}$ \\
\hline $\mathrm{F}$ & $\begin{array}{c}\text { Wetzel and } \\
\text { Penhale } 1979 \text { [171] }\end{array}$ & $\begin{array}{c}\text { Puget Sound and } \\
\text { northern Gulf of Mexico, } \\
\text { USA; Bimini } \\
\text { Harbor, Bahamas }\end{array}$ & Stable isotope tracers & $\begin{array}{l}\text { Halodule wrightii, } \\
\text { Thalassia testudinum, } \\
\text { Zostera marina }\end{array}$ & $\begin{array}{c}\text { Transport and } \\
\text { excretion of carbon } \\
\text { by seagrasses and } \\
\text { their epiphytes }\end{array}$ & $\begin{array}{l}\text { Phyllosphere, } \\
\text { rhizosphere }\end{array}$ & $\begin{array}{c}\text { Large portion of the inorganic carbon } \\
\text { taken up by the rooting tissue was } \\
\text { transported through the leaves and } \\
\text { released into the water. }\end{array}$ \\
\hline $\mathrm{F}$ & Williams et al., 2009 [172] & Florida Bay, USA & $\begin{array}{l}\text { Stable carbon isotope } \\
\text { ratios in phospholipid } \\
\text { fatty acids }\end{array}$ & Thalassia testudinum & $\begin{array}{l}\text { Pelagic, epiphytic, } \\
\text { and sediment } \\
\text { surface bacteria }\end{array}$ & Phyllosphere & $\begin{array}{l}\text { Bacterial communities consistently } \\
\text { incorporated seagrass-derived } \\
\text { organic matter (13-67\% of } \\
\text { bacterial-specific stable carbon } \\
\text { isotopic signatures). }\end{array}$ \\
\hline $\mathrm{s}$ & $\begin{array}{l}\text { Bengtsson et al., } \\
2017 \text { [173] }\end{array}$ & Baltic Sea, Germany & $\begin{array}{l}\text { Amplicon sequencing } \\
\text { of } 16 \mathrm{~S} \text { and } 18 \mathrm{~S} \\
\text { rRNA genes }\end{array}$ & Zostera marina & $\begin{array}{l}\text { Bacteria and } \\
\text { Eukaryotes }\end{array}$ & Phyllosphere & $\begin{array}{l}\text { Observed local variation of } \\
\text { microbiomes and found correlation } \\
\text { between prokaryotic microbiome and } \\
\text { eukaryotic epibiont communities. }\end{array}$ \\
\hline $\mathrm{s}$ & Bourque et al., 2015 [124] & Biscayne Bay, USA & T-RFLP & Thalassia testudinum & Bacteria & Rhizosphere & $\begin{array}{l}\text { Evaluated two restoration methods } \\
\text { and found that undisturbed reference } \\
\text { seagrass sediments had more } \\
\text { complex microbial communities than } \\
\text { disturbed and restoration sites. }\end{array}$ \\
\hline $\mathrm{s}$ & Cifuentes et al., 2000 [174] & $\begin{array}{c}\text { Bassin } \\
\text { d'Arcachon, France }\end{array}$ & $\begin{array}{l}\text { Sanger sequencing of } \\
\text { 16S rRNA genes, } \\
\text { clone libraries }\end{array}$ & Zostera noltii & $\begin{array}{l}\text { Bacteria } \\
\text { and Archaea }\end{array}$ & $\begin{array}{l}\text { Endosphere, } \\
\text { rhizosphere }\end{array}$ & $\begin{array}{l}\text { Report sulfate-reducing bacteria and } \\
\text { S-oxidizing endosymbionts, } \\
\text { as well as members of } \\
\text { Crenarchaeota and Euryarchaeota. }\end{array}$ \\
\hline
\end{tabular}


Table 2. Cont

\begin{tabular}{|c|c|c|c|c|c|c|c|}
\hline S & $\begin{array}{l}\text { Crump and } \\
\text { Koch } 2008 \text { [175] }\end{array}$ & Chesapeake Bay, USA & $\begin{array}{l}\text { PCR-DGGE and } \\
\text { Sanger sequencing of } \\
\text { clone libraries }\end{array}$ & Zostera marina & Bacteria & $\begin{array}{l}\text { Phyllosphere, } \\
\text { rhizosphere }\end{array}$ & $\begin{array}{l}\text { Leaves were dominated by typical } \\
\text { marine Alphaproteobacteria, while } \\
\text { roots hosted a diverse } \\
\text { microbial assemblage. }\end{array}$ \\
\hline S & Cúcio et al., 2016 [176] & $\begin{array}{l}\text { North-eastern Atlantic } \\
\text { Ocean }\end{array}$ & $\begin{array}{l}\text { Amplicon sequencing } \\
\text { of } 16 \mathrm{~S} \text { rRNA genes }\end{array}$ & $\begin{array}{c}\text { Zostera marina, Z. } \\
\text { noltii, Cymodocea } \\
\text { nodosa }\end{array}$ & Bacteria & Rhizosphere & $\begin{array}{l}\text { Rhizobiomes were similar in one } \\
\text { geographic region, but were } \\
\text { significantly different from the } \\
\text { sediment bacterial communities. }\end{array}$ \\
\hline S & $\begin{array}{c}\text { Donnelly and Herbert } \\
1999 \text { [177] }\end{array}$ & $\begin{array}{c}\text { Bassin } \\
\mathrm{d}^{\prime} \text { Arcachon, France }\end{array}$ & $\begin{array}{l}\text { Cultivation; light } \\
\text { and scanning } \\
\text { electron microscopy }\end{array}$ & Zostera noltii & Bacteria & Rhizosphere & $\begin{array}{l}\text { Sulfate reducing bacteria were } \\
\text { identified as the key group of } \\
\text { bacteria involved in } N \text {-fixation } \\
\text { in the rhizosphere. }\end{array}$ \\
\hline S & Ettinger et al., 2017 [178] & Bodega Bay, USA & $\begin{array}{l}\text { Amplicon sequencing } \\
\text { of } 16 \mathrm{~S} \text { rRNA genes }\end{array}$ & Zostera marina & Bacteria & $\begin{array}{l}\text { Phyllosphere, } \\
\text { rhizosphere }\end{array}$ & $\begin{array}{c}\text { Taxa that differ significantly between } \\
\text { sample types and sites are closely } \\
\text { related to ones commonly associated } \\
\text { with various aspects of sulfur and } \\
\text { nitrogen metabolism. }\end{array}$ \\
\hline S & $\begin{array}{l}\text { Fahimipour et al., } \\
2017 \text { [179] }\end{array}$ & $\begin{array}{l}\text { Multiple locations } \\
\text { across the } \\
\text { Northern Hemisphere }\end{array}$ & $\begin{array}{l}\text { Amplicon sequencing } \\
\text { of 16S rRNA genes }\end{array}$ & Zostera marina & Bacteria & $\begin{array}{l}\text { Phyllosphere, } \\
\text { rhizosphere }\end{array}$ & $\begin{array}{c}\text { Provides evidence for a core eelgrass } \\
\text { root microbiome (Sulfurimonas the } \\
\text { most dominant taxon). }\end{array}$ \\
\hline $\mathrm{s}$ & $\begin{array}{l}\text { Glazebrook et al., } \\
\quad 1996 \text { [180] }\end{array}$ & Pelican Banks, Australia & $\begin{array}{l}\text { Fluorescent microscopy } \\
\text { studies with } \\
\text { labeled antibodies } \\
\end{array}$ & Zostera capricorni & Alteromonas sp. & Rhizosphere & $\begin{array}{l}\text { Members of Alteromonas sp. were } \\
\text { more abundant in rhizosphere } \\
\text { than in bare sediment. }\end{array}$ \\
\hline s & Gnavi et al., 2014 [181] & $\begin{array}{l}21 \text { isolates obtained by } \\
\text { Panno et al., } 2013\end{array}$ & $\begin{array}{l}\text { Sanger sequencing of } \\
\text { ITS and } 28 \mathrm{~S} \\
\text { rRNA genes }\end{array}$ & Posidonia oceanica & Fungi & $\begin{array}{l}\text { Phyllosphere, } \\
\text { rhizosphere }\end{array}$ & $\begin{array}{l}\text { Identified several putative new } \\
\text { species belonging to orders } \\
\text { Pleosporales, Capnodiales } \\
\text { and Helotiales. }\end{array}$ \\
\hline $\mathrm{s}$ & $\begin{array}{l}\text { Green-García and } \\
\text { Engel } 2012 \text { [182] }\end{array}$ & Cedar Key, USA & $\begin{array}{l}\text { Sanger sequencing of } \\
\text { 16S rRNA genes, } \\
\text { clone libraries }\end{array}$ & $\begin{array}{l}\text { Thalassia } \\
\text { testudinum }\end{array}$ & Bacteria & Rhizosphere & $\begin{array}{l}41 \% \text { of the clones were more closely } \\
\text { related to each other than to } \\
\text { sequences retrieved from the } \\
\text { other habitats. }\end{array}$ \\
\hline $\mathrm{s}$ & $\begin{array}{l}\text { Jankowska et al., } \\
2015 \text { [183] }\end{array}$ & $\begin{array}{l}\text { Southern Baltic } \\
\text { Sea, Poland }\end{array}$ & $\begin{array}{l}\text { Epifluorescence } \\
\text { microscopy }\end{array}$ & Zostera marina & Bacteria & Rhizosphere & $\begin{array}{l}\text { Reported significantly higher } \\
\text { bacterial cell numbers and bacteria } \\
\text { biomass in rhizosphere } \\
\text { compared to bare sediments. }\end{array}$ \\
\hline s & Jensen et al., 2007 [184] & $\begin{array}{c}\text { Roskilde } \\
\text { Fjord, Denmark }\end{array}$ & $\begin{array}{l}\text { T-RFLP and Sanger } \\
\text { sequencing of } \\
\text { clone libraries }\end{array}$ & Zostera marina & Bacteria & Rhizosphere & $\begin{array}{l}\text { Bacterial community associated with } \\
\text { the roots of } Z \text {. marina differs from the } \\
\text { bacterial community in the } \\
\text { bulk sediment. }\end{array}$ \\
\hline S & Jiang et al., 2015 [185] & Xincun Bay, China & $\begin{array}{l}\text { Cultivation and } \\
\text { Sanger sequencing of } \\
16 \mathrm{~S} \text { rRNA genes }\end{array}$ & $\begin{array}{l}\text { Cymodocea rotundata, } \\
\text { Enhalus acoroides, } \\
\text { Thalassia hemperichii }\end{array}$ & Bacteria & Phyllosphere & $\begin{array}{c}\text { Diversity of the bacterial } \\
\text { communities in the sediment was } \\
\text { higher than that associated } \\
\text { with seagrass. }\end{array}$ \\
\hline
\end{tabular}


Table 2. Cont.

\begin{tabular}{|c|c|c|c|c|c|c|c|}
\hline $\mathrm{s}$ & Kurilenko et al., 2007 [186] & $\begin{array}{l}\text { Troitza Bay, Gulf of } \\
\text { Peter the Great, } \\
\text { Pacific Ocean }\end{array}$ & $\begin{array}{c}\text { Cultivation } \\
\text { based experiments }\end{array}$ & Zostera marina & Bacteria & Phyllosphere & $\begin{array}{l}\text { Demonstrated symbiotrophic } \\
\text { relationships between seagrass and } \\
\text { epiphytic bacteria } \\
\text { (selective adhesion). }\end{array}$ \\
\hline $\mathrm{s}$ & Ling et al., 2015 [187] & Xincun Bay, China & $\begin{array}{c}\text { PCR-DGGE, } \\
\text { quantitative PCR and } \\
\text { Sanger sequencing of } \\
\text { clone libraries }\end{array}$ & Enhalus acoroides & Fungi & Rhizosphere & $\begin{array}{l}\text { Fungal community of rhizosphere } \\
\text { changed significantly in response to } \\
\text { polycyclic aromatic hydrocarbons. }\end{array}$ \\
\hline $\mathrm{s}$ & Mejia et al., 2016 [188] & Gulf of Aqaba, Israel & $\begin{array}{l}\text { Amplicon sequencing } \\
\text { of } 16 \mathrm{~S} \text { rRNA genes }\end{array}$ & Halophila stipulacea & Bacteria & $\begin{array}{l}\text { Phyllosphere, } \\
\text { rhizosphere }\end{array}$ & $\begin{array}{l}\text { Proposed assessing the ecological } \\
\text { status of seagrasses using } \\
\text { their microbiome. }\end{array}$ \\
\hline $\mathrm{s}$ & Nielsen et al., 1999 [189] & $\begin{array}{c}\text { Lørgstrar } \\
\text { Broad, Denmark }\end{array}$ & Cultivation & Zostera marina & Sulfate reducers & Rhizosphere & $\begin{array}{l}\text { Isolated a novel species of the } \\
\text { genus Desulfovibrio. }\end{array}$ \\
\hline $\mathrm{s}$ & Novak 1984 [190] & Gulf of Naples, Italy & $\begin{array}{c}\text { Scanning } \\
\text { electron microscopy }\end{array}$ & Posidonia oceanica & $\begin{array}{c}\text { Epiphytic } \\
\text { microorganisms }\end{array}$ & Phyllosphere & $\begin{array}{l}\text { Observed dynamically changing } \\
\text { system of interactions between the } \\
\text { host plant, environmental and } \\
\text { epiphytic community (also within). }\end{array}$ \\
\hline $\mathrm{s}$ & Panno et al., 2013 [191] & Riva Trigoso Bay, Italy & $\begin{array}{l}\text { Cultivation, } \\
\text { microscopy, Sanger } \\
\text { sequencing of ITS }\end{array}$ & Posidonia oceanica & Fungi & $\begin{array}{l}\text { Phyllosphere, } \\
\text { rhizosphere }\end{array}$ & $\begin{array}{c}\text { Mycoflora associated to } P \text {. oceanica is } \\
\text { very rich and characterized by fungi } \\
\text { that are able to degrade and detoxify } \\
\text { lignocellulose residues in presence of } \\
\text { high salt concentrations. }\end{array}$ \\
\hline $\mathrm{s}$ & Sun et al., 2015 [192] & $\begin{array}{l}\text { Swan Lake, } \\
\text { Rongcheng Bay, China }\end{array}$ & $\begin{array}{l}\text { Amplicon sequencing } \\
\text { of } 16 \mathrm{~S} \text { rRNA genes }\end{array}$ & Zostera marina & Bacteria & Rhizosphere & $\begin{array}{l}\text { Metabolically versatile and } \\
\text { oxygen-tolerant anaerobic bacterial } \\
\text { taxa were enriched in } \\
\text { vegetated sediments. }\end{array}$ \\
\hline $\mathrm{s}$ & Weidner et al., 1996 [193] & Gulf of Aqaba, Israel & $\begin{array}{c}\text { ARDRA } \\
\text { (amplified rDNA } \\
\text { restriction analysis) }\end{array}$ & Halophila stipulacea & Bacteria & Phyllosphere & Improvement of the ARDRA method. \\
\hline
\end{tabular}




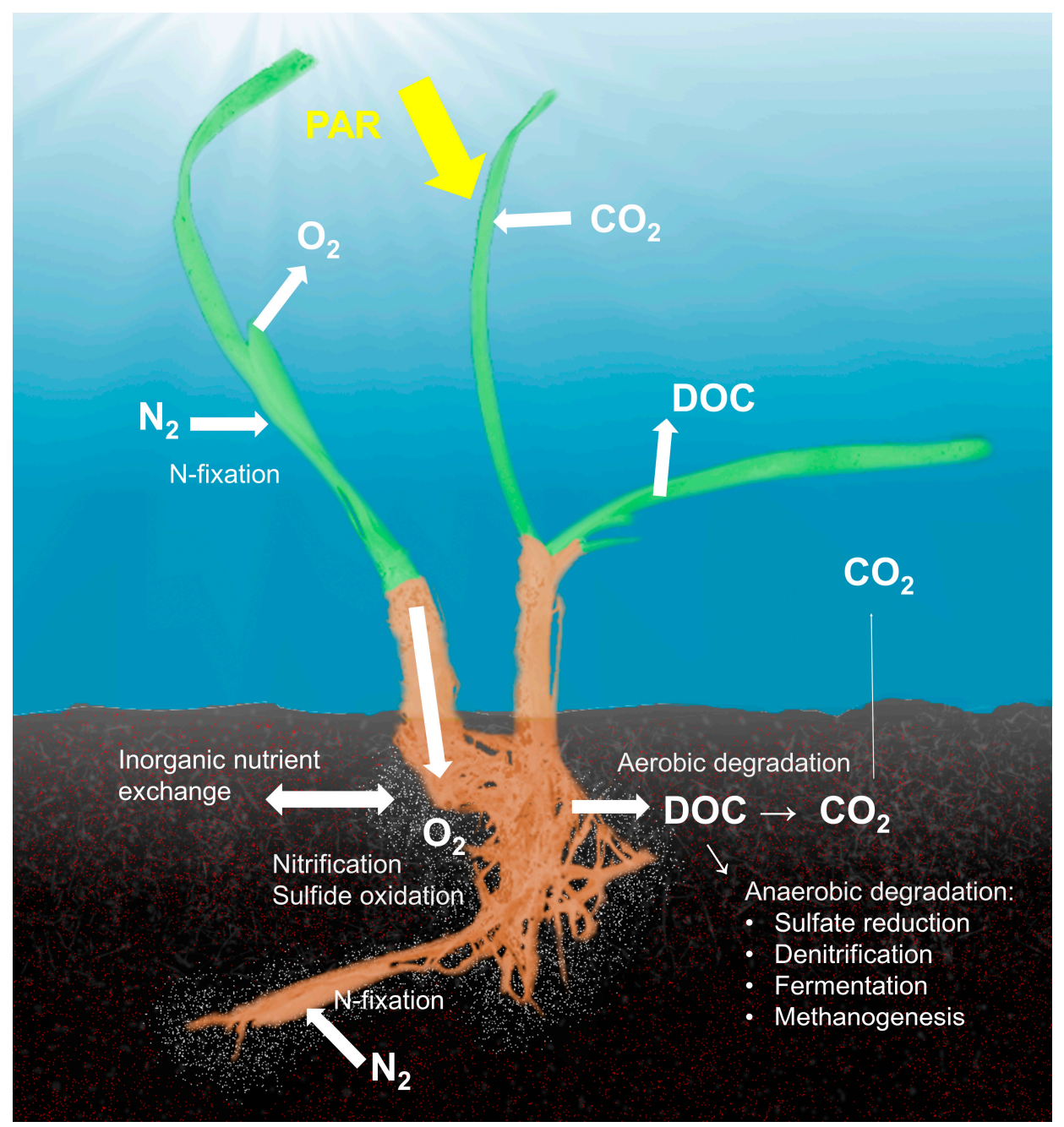

Figure 1. The most important interconnected processes within the seagrass holobiont are related to processes in the carbon-, nitrogen- and sulfur cycles. Photosynthetically active radiation (PAR) determines the photosynthetic activity of the seagrass plant that determines how much carbon dioxide is fixed, how much dissolved organic carbon (DOC) is exuded from the leaves and root system, and how much oxygen is transported into the rhizosphere. Oxygen transportation into the rhizosphere alters the redox conditions in the rhizosphere, differentiating it from the surrounding sediments that are usually anoxic and sulfidic.

\subsection{Carbon Cycle}

The physico-chemical parameters in the sediments are modified considerably by seagrasses. The diel photosynthetic activity of seagrasses is reflected in the amounts of dissolved organic carbon (DOC) and oxygen that are exuded through the roots and leaves [162,165,167,171]. Bacterial production rates can be two-fold higher during noon compared to nighttime in the seagrass rhizosphere, as opposed to nearby non-vegetated sediments [162,194]. At least for epiphytic bacteria on Zostera marina leaves, these exudates can account for most of the carbon needs [156]. In contrast, stable carbon isotope experiments carried out by Boschker et al. [47] in eutrophic ecosystems showed that seagrass-derived DOC in the sediments of Zostera spp. meadows only played a minor role for bacterial growth, and the authors suggested benthic algae as the main carbon source. However, subsequent studies carried out in oligotrophic seagrass beds found that seagrass-exuded DOC can be an important source of carbon for bacteria in the sediments [151,152,154]. Detrital plant material also adds carbon and other nutrients to the sediments of seagrass beds. 


\subsection{Nitrogen Cycle}

Caffrey and Kemp [148] demonstrated that nitrification, denitrification and ammonification rates in the rhizosphere of $Z$. marina were significantly higher than in bare sediments, and that these processes were correspondingly influenced by the concentration of nitrate, inputs of organic nitrogen, and the release of $\mathrm{O}_{2}$ through plant roots. Ammonification is an important process catalyzed by the microbiome to cycle nitrogen species in seagrass systems, with the highest rates of ammonification having been recorded during the active growth season as seagrass biomass has a high seasonal turnover $[148,168]$.

Nitrogen-fixing (diazotrophic) bacteria and archaea also play a very beneficial role for their host, especially in oligotrophic seagrass beds where nitrogen might be limiting. $N$-fixing bacteria are up to 300 times more abundant in the rhizosphere of T. testudinum and Z. marina than in bare sediments [164]. Diverse diazotrophic assemblages have been identified based on nifH gene sequences, which encode for the nitrogenase iron protein $[137,138]$. Sun et al. [192] could show that the copy numbers of nifH were significantly higher in eelgrass-vegetated meadows than in the surrounding sediments. Ammonia from nitrogen-fixing microorganisms in the rhizosphere can provide anywhere between a third to $100 \%$ of the nitrogen requirements of the plant [164,192,195-197]. Nitrogen fixation is not limited to the rhizosphere and high nitrogen fixation activities (up to $15.2 \mathrm{mg} \mathrm{N} \mathrm{m}^{-2} \mathrm{~d}^{-1}$ ) have also been detected in the phyllosphere of P. oceanica in the Mediterranean Sea, potentially supplying the total nitrogen demand of the plant [137].

Similar to circadian patterns in bacterial production, diel cycles and seasonal changes in nitrogen fixation rates have been observed in sediments of seagrass beds [160]. Welsh et al. [196] and Agawin et al. [137] summarized many studies carried out in seagrass beds that demonstrate that $\mathrm{N}$-fixation rates can be even two magnitudes higher in conditions with more light (highest rates in the summer and daytime). In Biscayne Bay, $N$-fixation rates of the Z. marina rhizosphere can be 20-fold higher in the summer compared to winter. Temperature was identified as an important factor for this change and it was shown that a decrease of $10{ }^{\circ} \mathrm{C}$ halved the rates [149]. Higher photosynthetic activity of the seagrass plant means that more oxygen is exuded to the rhizosphere $[163,166]$, which has an impact on nitrogen fixation as nitrogenases can be irreversibly inhibited by dioxygen. Several mechanisms can be used by diazotrophs to overcome this, and Agawin et al. [137] suggested that $\mathrm{N}$-fixing bacteria in the seagrass rhizosphere reside in anoxic microzones. Two-dimensional planar analyses of $Z$. marina root systems have shown that radial oxygen loss is not uniform and small areas in the tips of new roots are the main source of leakage, which can create suitable niches for anaerobic microbes along other parts of the roots $[150,184]$.

\subsection{Sulfur Cycle}

Sediments in seagrass meadows are often anoxic and sulfate-reduction rates are many-fold higher in the rhizosphere than below the root zone or adjacent, non-vegetated sediments [153,158,198]. A recent publication summarized depth-integrated sulfate reduction rates reported by 16 previous studies carried out in seagrass beds [155]. Lactate- and acetate-utilizing sulfate-reducing bacteria are an order of magnitude more abundant in the Halodule wrightii rhizosphere than in nearby bare sediments [140]. Diel cycles have also been identified to impact sulfate reduction in the rhizosphere with rates nearly doubling during daytime $[145,161,199,200]$. In addition, sediments of T. testudinum meadows show strong seasonal patterns, as sulfate reduction rates can increase two-fold when seagrass is more actively growing $[145,159,198,201]$. Similar to nitrogen fixation, this process should be inhibited by the presence of oxygen, but root surface-associated sulfate reducers demonstrate a high tolerance towards oxygen [144]. Niches with reduced oxygen concentrations are formed by the activity of aerobic metabolism of microbes in the rhizosphere, but are also present in parts of the rhizosphere with lower oxygen leakage $[150,184]$.

Sulfate reduction produces sulfide, a strong phytotoxin [202] that can lead to major seagrass die-off events $[81,203]$. Seagrasses are able to detoxify lower levels of sulfide through oxygenating their roots [204], integrating reduced sulfur into their biomass as thiols [205], and through the detoxifying 
activity of endosymbiotic, sulfide-oxidizing bacteria in lucinid bivalves, which colonize sediments of seagrass beds [2]. Sulfate-reducing bacteria are a dominant group involved in nitrogen fixation in the rhizosphere of Zostera noltii and other seagrasses $[160,177,196]$, which could mean that for the seagrass holobiont, the presence of these bacteria is overall beneficial, especially when sulfide is neutralized by other members of the microbiome. Sulfur-oxidizing bacteria, which convert sulfide into non-toxic sulfate, are present in the rhizosphere and likely benefit seagrasses by detoxifying low levels of hydrogen sulfide. This hypothesis has been discussed by several recent papers that have observed a high abundance of presumably sulfide-oxidizing taxa within the rhizome-associated bacterial communities (e.g., [176,178,179]). Jensen et al. [184] suggested that the presence of the roots stimulates the growth of potential symbiotic sulfur-oxidizing taxa.

\subsection{Protective Functions of the Seagrass Microbiome}

Removal of phytotoxic compounds is an important function of the seagrass microbiome that benefits and increases the ecological fitness of the host. The symbiotic relationship between the seagrass plant and sulfur-oxidizers capable of detoxifying sulfide is discussed above. Similar mechanisms of bacterial detoxification of sulfide in the rhizosphere of rice have been known for 40 years [206]. Another phytotoxin, ethanol, is produced by the seagrass plant itself at night, when root tissues switch to fermentation due lack of oxygen [207] Cúcio and colleagues [176] suggested that sulfur-reducing members of Desulfobacteraceae can use ethanol as an electron donor and are able to detoxify it during night time.

Seagrasses use a combined strategy of $\mathrm{H}_{2} \mathrm{O}_{2}$ production and caspase activity to combat fungal infections [208]. Cúcio et al. [176] suggested that some members of Actinobacteria in the seagrass rhizosphere might also provide protection against pathogens for the host. Some symbiotic bacterial epiphytes and especially endophytes of the seagrass Enhalus acoroides are natural antifoulants against harmful biofilm-forming bacteria [141].

While these studies hypothesize that microorganisms within the seagrass holobiont act as a defense mechanism, to the best of our knowledge this has not been convincingly proven to be a general feature of the seagrass microbiome.

\section{Structure of the Seagrass Microbiome}

The phylogenetic composition of microbial communities is interconnected with their functional capabilities. In order to understand the phylogenetic assembly of seagrass-associated microbial communities, the three major compartments of the microbiome (rhizosphere, endosphere and phyllosphere) have to be considered separately, because they represent different habitats with distinct interactions between the biotic and abiotic environments (Figure 2). In general, the phyllosphere offers niches that can be occupied by a larger variety of generalist taxa (like many aerobic organoheterotrophs), while the endosphere and rhizosphere provide niches to more specialized species (including organisms involved in transformations of different nitrogen and sulfur species). 


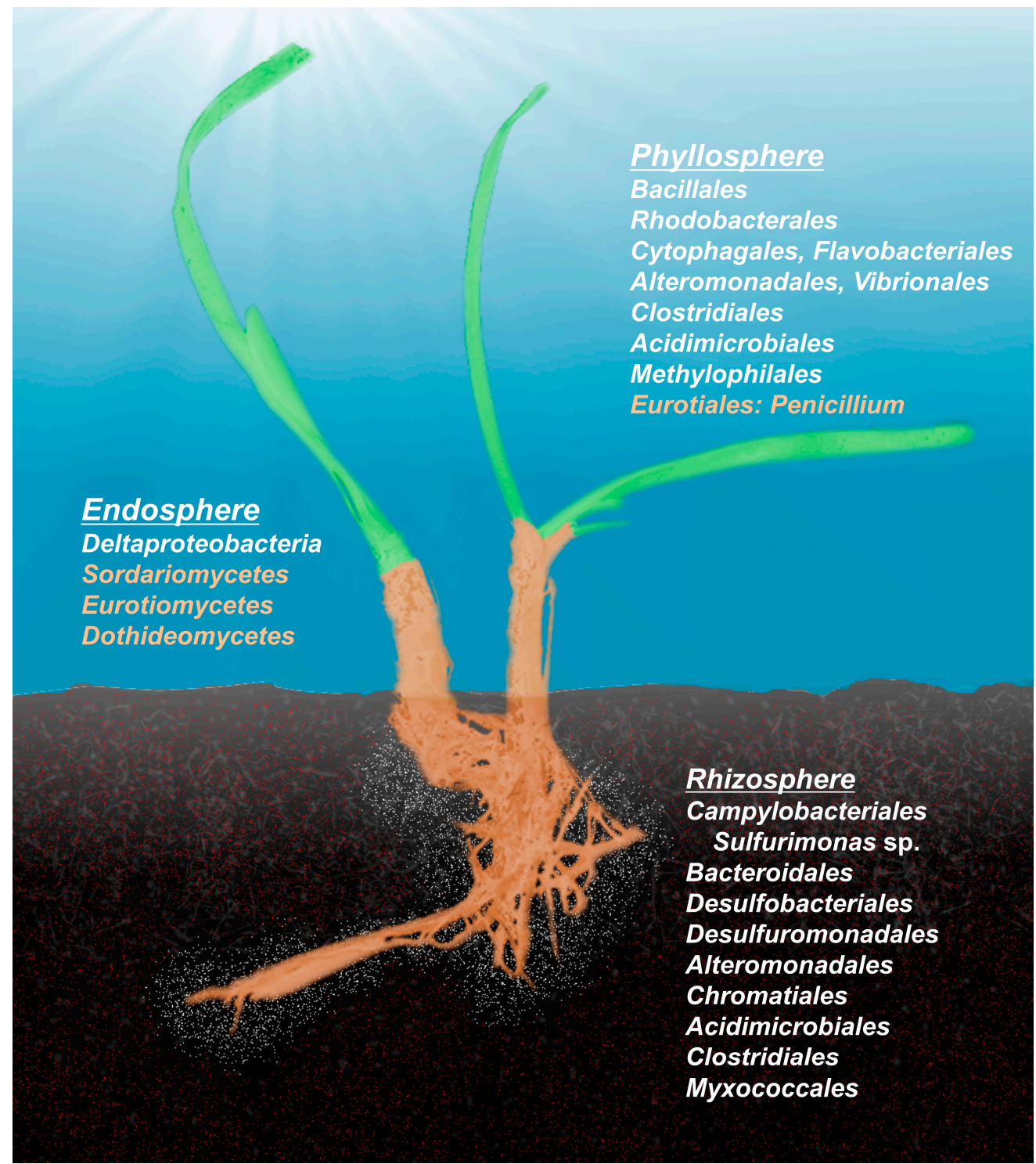

Figure 2. The most abundant bacterial (white fonts) and fungal groups (orange fonts) identified within different compartments of the seagrass holobiont.

\subsection{Phyllosphere}

A recent global-scale study of the Z. marina microbiome revealed high variability and spatial turnover among leaf bacterial communities, which strongly resembled bacterioplankton communities of the adjacent coastal seawater [179]. Leaf-enriched taxa were dominated by members of the Betaproteobacteria, Planctomycetia, OM190, and Acidimicrobiia [179]. Similar results were obtained by investigating the leaf microbiome of Z. marina in coastal sites of the Baltic Sea, where the most abundant taxa matched key chemoorganotrophic bacterioplankton groups of the water, such as members of Alphaproteobacteria, Sphingobacteria, Flavobacteria and Verrucomicrobia $[173,183,209,210]$.

Bengtsson et al. [173] demonstrated a co-occurrence of epibiotic eukaryotes and members of the bacterial microbiome on the leaves, with extensive variability in both groups correlated to water depth, leaf surface area and chlorophyll a content in the leaf biofilm. Previously, Halophila stipulacea leaves were shown to be colonized by bacteria associated with marine snow [193]. Similarly, taxa that also attach to particles and phytoplankton cells, including members of Bacteroidetes, were reported on leaves of Z. marina $[186,211]$. Together, these results indicate that the seagrass phyllosphere is mostly 
colonized by the surrounding heterotrophic bacterioplankton, and especially by groups that usually possess the ability to degrade polymers and are known to attach to surfaces and form biofilms (Figure 1). Marine fungi with similar metabolic capabilities are also frequent members of the phyllosphere of seagrasses $[142,173,181,187,191]$. At higher taxonomic ranks, the phyllosphere of Z. marina resembles the microbiomes of various marine algae [178]. Roth-Schulz and colleagues [212] concluded that seagrass phyllosphere communities are assembled mainly by taxa that specialize in surface-associated life-styles, but that in some cases certain host-specific features, such as the capability to degrade specific polysaccharides that are present in this environment, play an important role.

\subsection{Rhizosphere}

Overall, the bacterial abundances and biomass in the rhizosphere exceed those found in nearby non-vegetated sediments by about two-fold, but these numbers vary depending on the season $[140,147,177,183,185,198]$. In contrast to the phyllosphere microbiome, which resembles the surrounding bacterioplankton community, studies utilizing next-generation technologies have demonstrated that the seagrass rhizosphere microbiome exhibits significant differences in composition compared to adjacent vegetated sediment communities [124,176,178,184]. A global-scale study of the Z. marina microbiome revealed that the rhizosphere microbiome harbored a higher diversity and significant differences in composition compared to the phyllosphere [179]. However, the diversity of rhizosphere communities can be reduced by physical and chemical disturbances, including human activities [213]. Ettinger et al. [178] demonstrated significant shifts in microbial community composition within different areas of the rhizosphere itself, especially between the edge and the center of the rhizosphere. The study also revealed that sediment communities were much more diverse than rhizosphere communities, which indicates selective forces within the rhizosphere for certain taxa. One selecting factor is probably the labile organic matter that is being exuded from the roots, since certain heterotrophic organisms, such as members of the Bacteroidales and Myxococcales, are abundant in the seagrass rhizosphere [178,192].

Another important factor influencing the rhizosphere community composition is the generally anoxic condition of the sediments that are inhabited by seagrasses. Seagrass roots emit oxygen into the sediment [150,214] and thereby create a redox gradient in the rhizosphere, which forms specific niches for metabolically diverse bacteria. These redox gradients are essential for the presence and the activity of chemolithotrophic microorganisms. Consequently, seagrass rhizosphere microbiomes harbor a mix of aerobic and anaerobic members of the classes Alpha-, Gamma-, Delta- and Epsilonproteobacteria, Bacteroidetes and Clostridiales (Figure 1; [174-176,178,179,182,184,188,192]). Cúcio et al. [176] identified almost 3500 different taxa (97\% 16 rRNA gene sequence similarity) from the rhizospheres of Z. marina, Z. noltii, and Cymodocea nodosa across the North-eastern Atlantic Ocean, out of which only 101 taxa were present in all samples (including replicates) and were considered as part of the core seagrass rhizobiome; 64\% of these core taxa belong to Alpha-, Gamma-, Delta-, and Epsilonproteobacteria. The authors suggested that the main driver of the composition of seagrass rhizobiome communities is the host's metabolism and that the resulting metabolic niches are not necessarily specific to a certain seagrass species. However, significant differences in the microbial community composition of a single seagrass species can be detected among different sampling sites (and their respective sediments), which indicates the influence of the surrounding sediments as a source for recruitment. Interestingly, many core taxa identified in this study were presumed to be active in the sulfur cycle and are likely directly involved in detoxification of sulfide or sulfur.

\subsection{Endosphere}

Only limited information is available on endophytic microbes of seagrasses. Although previous experiments showed that only low activities of sulfate reducers can be detected in the cortex cells of Z. marina [145], Küsel et al. [140] demonstrated that sulfate reducers colonize $60 \%$ of the deepest cortex cells of Halodule wrightii. This study also reported the presence of acetogenic bacteria in the outermost cortex cell layers. Furthermore, the sulfate-reducing and N-fixing bacterium Desulfovibrio zosterae 
was isolated from surface-sterilized roots of Z. marina [189]. Additional studies identified organisms that were closely related to known endophytes: Cifuentes et al. [174] investigated sliced sections of rhizome material from the seagrass Zostera noltii and identified five species of Gammaproteobacteria closely related to S-oxidizing endosymbionts; Sakayaroj et al. [215] demonstrated that the seagrass Enhalus acoroides harbors a wide diversity of fungal endophytes, with $93 \%$ of them belonging to the classes Sordariomycetes, Eurotiomycetes and Dothideomycetes; two studies have isolated and identified fungi (members of Dothideomycetes and Leotiomycetes) from the rhizosphere of P. oceanica and determined that some isolates were closely related to endophytic species [181,191].

\section{Conclusions about the Current Knowledge of Seagrass Microbiomes}

Research over the past 40 years has shown elevated microbial activity within the seagrass holobiont compared to microbial communities occupying nearby non-vegetated environments. These activities include many important biogeochemical transformations within the nitrogen, sulfur and carbon cycles and are impacted by the physiology of the seagrass host. Some microbial activities, such as $\mathrm{N}$-fixation in oligotrophic ecosystems or sulfide-oxidation in seabeds suffering from prolonged anoxia, can clearly improve the host's fitness and its adaptation to certain habitats. The phylogenetic composition of the seagrass microbiome is influenced by microbial communities occupying the surrounding environment, but also significantly differs from them. The presence of a few reoccurring core taxa indicates specific niches provided by seagrasses. However, most ecological functions of the seagrass microbiome, including the core microbiome, and their interactions within the seagrass host are still unknown. No study so far has systematically addressed taxonomy and functional profile of the seagrass microbiome in parallel. Such studies would provide clues for key host-microbe interactions and further elucidate the multi-faceted roles of the microbiome in maintaining a healthy seagrass holobiont. These studies could improve our understanding of current and future seagrass die-off events, and possibly help provide strategies to mitigate or even avoid them.

Acknowledgments: This work was supported by the USDA National Institute of Food and Agriculture, Hatch project FLA-FTL-005631.

Conflicts of Interest: The authors declare no conflicts of interest.

\section{References}

1. Olsen, J.L.; Rouze, P.; Verhelst, B.; Lin, Y.C.; Bayer, T.; Collen, J.; Dattolo, E.; De Paoli, E.; Dittami, S.; Maumus, F.; et al. The Genome of the Seagrass Zostera marina Reveals Angiosperm Adaptation to the Sea. Nature 2016, 530, 331-335. [CrossRef] [PubMed]

2. Van der Heide, T.; Govers, L.L.; de Fouw, J.; Olff, H.; van der Geest, M.; van Katwijk, M.M.; Piersma, T.; van de Koppel, J.; Silliman, B.R.; Smolders, A.J.P.; et al. A Three-Stage Symbiosis Forms the Foundation of Seagrass Ecosystems. Science 2012, 336, 1432-1434. [CrossRef] [PubMed]

3. Larkum, A.W.D.; Orth, R.J.; Duarte, C. (Eds.) Seagrasses: Biology, Ecology, and Conservation; Springer: Dordrecht, The Netherlands, 2006; p. 691.

4. Waycott, M.; Procaccini, G.; Les, D.H.; Reusch, T.B.H. Seagrass Evolution, Ecology and Conservation: A Genetic Perspective; Springer: Dordrecht, The Netherlands, 2007; pp. 25-50.

5. Den Hartog, C. The Sea-Grasses of the World; North-Holl. Publ. Co.: Amsterdam, The Netherlands; London, UK, 1970; p. 275.

6. Kuo, J.; Hartog, C.D. Seagrass morphology, anatomy, and ultrastructure. In Seagrasses: Biology, Ecologyand Conservation; Springer: Dordrecht, The Netherlands, 2007; pp. 51-87.

7. Duarte, C.M.; Middelburg, J.J.; Caraco, N. Major Role of Marine Vegetation on the Oceanic Carbon Cycle. Biogeosciences 2005, 2, 1-8. [CrossRef]

8. Charpy-Roubaud, C.; Sournia, A. The Comparative Estimation of Phytoplanktonic, Microphytobenthic and Macrophytobenthic Primary Production in the Oceans. Mar. Microb. Food Webs 1990, 4, 31-57.

9. Schubert, N.; Demes, K.W. Phenotypic Plasticity in the Marine Angiosperm Halophila Decipiens (Hydrocharitaceae, Streptophyta). Mar. Ecol. Prog. Ser. 2017, 575, 81-93. [CrossRef] 
10. Spalding, M.; Taylor, M.; Ravilious, C.; Short, F.; Green, E. The Distribution and Status of Seagrasses; University of Califiornia Press: Berkeley, CA, USA, 2003; pp. 5-26.

11. Short, F.; Carruthers, T.; Dennison, W.; Waycott, M. Global Seagrass Distribution and Diversity: A Bioregional Model. J. Exp. Mar. Biol. Ecol. 2007, 350, 3-20. [CrossRef]

12. Kirk, J.T.O. Light and Photosynthesis in Aquatic Ecosystems, 3rd ed.; Cambridge University Press: Cambridge, UK, 2011.

13. Reusch, T.B.H.; Bostrom, C. Widespread Genetic Mosaicism in the Marine Angiosperm Zostera marina is Correlated with Clonal Reproduction. Evol. Ecol. 2011, 25, 899-913. [CrossRef]

14. De Cock, A.W.A.M. Flowering, Pollination and Fruiting in Zostera marina L. Aquat. Bot. 1980, 9, $201-220$. [CrossRef]

15. Arnaud-Haond, S.; Moalic, Y.; Hernandez-Garcia, E.; Eguiluz, V.M.; Alberto, F.; Serrao, E.A.; Duarte, C.M. Disentangling the Influence of Mutation and Migration in Clonal Seagrasses Using the Genetic Diversity Spectrum for Microsatellites. J. Hered. 2014, 105, 532-541. [CrossRef] [PubMed]

16. Nordlund, L.M.; Koch, E.W.; Barbier, E.B.; Creed, J.C. Seagrass Ecosystem Services and Their Variability across Genera and Geographical Regions. PLoS ONE 2016, 11, e0163091. [CrossRef] [PubMed]

17. Guannel, G.; Arkema, K.; Ruggiero, P.; Verutes, G. The Power of Three: Coral Reefs, Seagrasses and Mangroves Protect Coastal Regions and Increase Their Resilience. PLoS ONE 2016, 11, e0158094. [CrossRef] [PubMed]

18. Gullstrom, M.; de la Torre-Castro, M.; Bandeira, S.O.; Bjork, M.; Dahlberg, M.; Kautsky, N.; Ronnback, P.; Ohman, M.C. Seagrass Ecosystems in the Western Indian Ocean. Ambio 2002, 31, 588-596. [CrossRef] [PubMed]

19. Bertelli, C.M.; Unsworth, R.K.F. Protecting the Hand That Feeds Us: Seagrass (Zostera marina) Serves as Commercial Juvenile Fish Habitat. Mar. Pollut. Bull. 2014, 83, 425-429. [CrossRef] [PubMed]

20. Lilley, R.J.; Unsworth, R.K.F. Atlantic Cod (Gadus morhua) Benefits from the Availability of Seagrass (Zostera marina) Nursery Habitat. Glob. Ecol. Conserv. 2014, 2, 367-377. [CrossRef]

21. Hill, K. Indian River Lagoon Species Inventory; Smithsonian Marine Station: Fort Pierce, FL, USA, 2002; Available online: http:/ / www.sms.si.edu/irlspec/seagrass_habitat.htm (accessed on 21 October 2017).

22. McMahon, K.W.; Berumen, M.L.; Thorrold, S.R. Linking Habitat Mosaics and Connectivity in a Coral Reef Seascape. Proc. Natl. Acad. Sci. USA 2012, 109, 15372-15376. [CrossRef] [PubMed]

23. Ward, T.; Butler, E.; Hill, B. Environmental Indicators for National State of the Environment Reporting-Estuaries and the Sea; Australia: State of the Environment (Environmental Indicator Reports); Department of the Environment: Canberra, Australia, 1998.

24. Foden, J.; Brazier, D.P. Angiosperms (Seagrass) within the EU Water Framework Directive: A UK Perspective. Mar. Pollut. Bull. 2007, 55, 181-195. [CrossRef] [PubMed]

25. Duarte, C.M.; Marba, N.; Gacia, E.; Fourqurean, J.W.; Beggins, J.; Barron, C.; Apostolaki, E.T. Seagrass Community Metabolism: Assessing the Carbon Sink Capacity of Seagrass Meadows. Glob. Biogeochem. Cycles 2010, 24. [CrossRef]

26. Marba, N.; Arias-Ortiz, A.; Masque, P.; Kendrick, G.A.; Mazarrasa, I.; Bastyan, G.R.; Garcia-Orellana, J.; Duarte, C.M. Impact of Seagrass Loss and Subsequent Revegetation on Carbon Sequestration and Stocks. J. Ecol. 2015, 103, 296-302. [CrossRef]

27. Van der Heide, T.; Eklof, J.S.; van Nes, E.H.; van der Zee, E.M.; Donadi, S.; Weerman, E.J.; Olff, H.; Eriksson, B.K. Ecosystem Engineering by Seagrasses Interacts with Grazing to Shape an Intertidal Landscape. PLoS ONE 2012, 7, e42060. [CrossRef] [PubMed]

28. Waycott, M.; Duarte, C.M.; Carruthers, T.J.B.; Orth, R.J.; Dennison, W.C.; Olyarnik, S.; Calladine, A.; Fourqurean, J.W.; Heck, K.L.; Hughes, A.R.; et al. Accelerating Loss of Seagrasses across the Globe Threatens Coastal Ecosystems. Proc. Natl. Acad. Sci. USA 2009, 106, 12377-12381. [CrossRef] [PubMed]

29. National Oceanic and Atmospheric Administration. Coastal Blue Carbon. Available online: http://www. habitat.noaa.gov/ coastalbluecarbon.html (accessed on 15 November 2017).

30. Mazarrasa, I.; Marba, N.; Lovelock, C.E.; Serrano, O.; Lavery, P.S.; Fourqurean, J.W.; Kennedy, H.; Mateo, M.A.; Krause-Jensen, D.; Steven, A.D.L.; et al. Seagrass Meadows as a Globally Significant Carbonate Reservoir. Biogeosciences 2015, 12, 4993-5003. [CrossRef] 
31. Fourqurean, J.; Johnson, B.; Kauffman, J.B.; Kennedy, H.; Lovelock, C.; Saintilan, N.; Alongi, D.M.; Cifuentes, M.; Copertino, M.; Crooks, S.; et al. Field Sampling of Vegetative Carbon Pools in Coastal Ecosystems; Conservation International, Intergovernmental Oceanographic Commission of UNESCO, International Union for Conservation of Nature: Arlington, VA, USA, 2014; pp. 67-108.

32. Fourqurean, J.W.; Duarte, C.M.; Kennedy, H.; Marba, N.; Holmer, M.; Mateo, M.A.; Apostolaki, E.T.; Kendrick, G.A.; Krause-Jensen, D.; McGlathery, K.J.; et al. Seagrass Ecosystems as a Globally Significant Carbon Stock. Nat. Geosci. 2012, 5, 505-509. [CrossRef]

33. Kennedy, H.; Bjork, M. Seagrass Meadows. In The Management of Natural Coastal Carbon Sinks; Laffoley, D.d'A., Grimsditch, G., Eds.; International Union for Conservation of Nature: Gland, Switzerland, 2009; pp. $23-29$.

34. Costanza, R.; d'Arge, R.; de Groot, R.; Farber, S.; Grasso, M.; Hannon, B.; Limburg, K.; Naeem, S.; O’Neill, R.V.; Paruelo, J.; et al. The Value of Ecosystem Services: Putting the Issues in Perspective. Ecol. Econ. 1998, 25, 67-72. [CrossRef]

35. Moore, K.A. Influence of Seagrasses on Water Quality in Shallow Regions of the Lower Chesapeake Bay. J. Coast. Res. 2004, 162-178. [CrossRef]

36. Reynolds, P.L. Seagrass and Seagrass Beds. Available online: http:/ /ocean.si.edu/seagrass-and-seagrassbeds (accessed on 21 October 2017).

37. Howard, J.L.; Creed, J.C.; Aguiar, M.V.P.; Fourqurean, J.W. $\mathrm{CO}_{2}$ released by Carbonate Sediment Production in Some Coastal Areas May Offset the Benefits of Seagrass "Blue Carbon" Storage. Assoc. Sci. Limnol. Oceanogr. 2017. [CrossRef]

38. Lovelock, C.E.; Atwood, T.; Baldock, J.; Duarte, C.M.; Hickey, S.; Lavery, P.S.; Masque, P.; Macreadie, P.I.; Ricart, A.M.; Serrano, O.; et al. Assessing the Risk of Carbon Dioxide Emissions from Blue Carbon Ecosystems. Front. Ecol. Environ. 2017, 15, 257-265. [CrossRef]

39. Pendleton, L.; Donato, D.C.; Murray, B.C.; Crooks, S.; Jenkins, W.A.; Sifleet, S.; Craft, C.; Fourqurean, J.W.; Kauffman, J.B.; Marba, N.; et al. Estimating Global "Blue Carbon" Emissions from Conversion and Degradation of Vegetated Coastal Ecosystems. PLoS ONE 2012, 7, e43542. [CrossRef] [PubMed]

40. Seagrasses. Available online: http://myfwc.com/research/habitat/seagrasses/\%0A (accessed on 11 September 2017).

41. Castelblanco-Martinez, D.N.; Barba, E.; Schmitter-Soto, J.J.; Hernandez-Arana, H.A.; Morales-Vela, B. The Trophic Role of the Endangered Caribbean Manatee Trichechus Manatus in an Estuary with Low Abundance of Seagrass. Estuar. Coasts 2012, 35, 60-77. [CrossRef]

42. Best, R.C. Foods and Feeding Habits of Wild and Captive Sirenia. Mamm. Rev. 1981, 11, 3-29. [CrossRef]

43. Lamb, J.B.; van de Water, J.; Bourne, D.G.; Altier, C.; Hein, M.Y.; Fiorenza, E.A.; Abu, N.; Jompa, J.; Harvell, C.D. Seagrass Ecosystems Reduce Exposure to Bacterial Pathogens of Humans, Fishes, and Invertebrates. Science 2017, 355, 731-733. [CrossRef] [PubMed]

44. Kannan, R.R.R.; Arumugam, R.; Anantharaman, P. Antibacterial Potential of Three Seagrasses against Human Pathogens. Asian Pac. J. Trop. Med. 2010, 3, 890-893. [CrossRef]

45. De los Santos, C.B.; Onoda, Y.; Vergara, J.J.; Perez-Llorens, J.L.; Bouma, T.J.; La Nafie, Y.A.; Cambridge, M.L.; Brun, F.G. A Comprehensive Analysis of Mechanical and Morphological Traits in Temperate and Tropical Seagrass Species. Mar. Ecol. Prog. Ser. 2016, 551, 81-94. [CrossRef]

46. De Falco, G.; Molinaroli, E.; Conforti, A.; Simeone, S.; Tonielli, R. Biogenic Sediments from Coastal Ecosystems to Beach-Dune Systems: Implications for the Adaptation of Mixed and Carbonate Beaches to Future Sea Level Rise. Biogeosciences 2017, 14, 3191-3205. [CrossRef]

47. Short, A.D. Beaches of the Western Australian Coast: Eucla to Roebuck Bay; Australian Beach Safety and Management Program; Sydney University Press: Sydney, Australia, 2005.

48. Unsworth, R.K.F.; Jones, B.L.; Cullen-Unsworth, L.C. Seagrass Meadows Are Threatened by Expected Loss of Peatlands in Indonesia. Glob. Chang. Biol. 2016, 22, 2957-2958. [CrossRef] [PubMed]

49. Tomascik, T.; Mah, A.J.; Nontji, A.; Moosa, M.K. The Ecology of the Indonesian Seas: Part Two; Periplus Edition (HK) Ltd.: Hong Kong, China, 1997.

50. Nurdin, N.; Riani, E.; Djuwita, I.; Budiharsono, S.; Purbayanto, A.; Asmus, H. Challenging for Seagrass Management in Indonesia. J. Coast. Dev. 2012, 15, 234-242.

51. Telesca, L.; Belluscio, A.; Criscoli, A.; Ardizzone, G.; Apostolaki, E.T.; Fraschetti, S.; Gristina, M.; Knittweis, L.; Martin, C.S.; Pergent, G.; et al. Seagrass Meadows (Posidonia oceanica) Distribution and Trajectories of Change. Sci. Rep. 2015, 5, 12505. [CrossRef] [PubMed] 
52. Orth, R.J.; Moore, K.A. Chesapeake Bay: An Unprecedented Decline in Submerged Aquatic Vegetation. Science 1983, 222, 51-53. [CrossRef] [PubMed]

53. Zieman, J.C.; Fourqurean, J.W.; Frankovich, T.A. Seagrass Die-off in Florida Bay: Long-Term Trends in Abundance and Growth of Turtle Grass, Thalassia testudinum. Estuaries 1999, 22, 460-470. [CrossRef]

54. Orth, R.J.; Carruthers, T.J.B.; Dennison, W.C.; Duarte, C.M.; Fourqurean, J.W.; Heck, K.L.; Hughes, A.R.; Kendrick, G.A.; Kenworthy, W.J.; Olyarnik, S.; et al. A Global Crisis for Seagrass Ecosystems. Bioscience 2006, 56, 987-996. [CrossRef]

55. Hall, M.O.; Furman, B.T.; Merello, M.; Durako, M.J. Recurrence of Thalassia testudinum Seagrass Die-off in Florida Bay, USA: Initial Observations. Mar. Ecol. Prog. Ser. 2016, 560, 243-249. [CrossRef]

56. Robblee, M.B.; Barber, T.R.; Carlson, P.R.; Durako, M.J.; Fourqurean, J.W.; Muehlstein, L.K.; Porter, D.; Yarbro, L.A.; Zieman, R.T.; Zieman, J.C. Mass Mortality of the Tropical Seagrass Thalassia testudinum in Florida Bay (USA). Mar. Ecol. Prog. Ser. 1991, 71, 297-299. [CrossRef]

57. Nordlund, L.; Erlandsson, J.; de la Torre-Castro, M.; Jiddawi, N. Changes in an East African Social-Ecological Seagrass System: Invertebrate Harvesting Affecting Species Composition and Local Livelihood. Aquat. Living Resour. 2010, 23, 399-416. [CrossRef]

58. De la Torre-Castro, M.; Ronnback, P. Links between Humans and Seagrasses-An Example from Tropical East Africa. Ocean Coast. Manag. 2004, 47, 361-387. [CrossRef]

59. Short, F.; Green, E.P. World Atlas of Seagrasses; University of California Press: Oakland, CA, USA, 2003.

60. Wakibya, J.G. The Potential Human-Induced Impacts on the Kenyan Seagrasses; UNESCO Report in Marine Sciences; United Nations Educational, Scientific and Cultural Organization: Paris, France, 1995; Volume 66, pp. 176-187.

61. Nasr, A.H.; Aleem, A.A. Ecological Studies of Some Marine Algae from Alexandria. Hydrobiologia 1949, 1, 251-281. [CrossRef]

62. Tackholm, V.; Tackholm, G.; Drar, M. Flora of Egypt; Fouad Univeristy I, Bulletin of the Faculty of Science: Cairo, Egypt, 1941; Volume 1, pp. 1-574.

63. Gordon, N.; Adams, J.B.; Bate, G.C. Epiphytes of the St. Lucia Estuary and Their Response to Water Level and Salinity Changes during a Severe Drought. Aquat. Bot. 2008, 88, 66-76. [CrossRef]

64. Halun, Z.; Terrados, J.; Borum, J.; Kamp-Nielsen, L.; Duarte, C.M.; Fortes, M.D. Experimental Evaluation of the Effects of Siltation-Derived Changes in Sediment Conditions on the Philippine Seagrass Cymodocea rotundata. J. Exp. Mar. Biol. Ecol. 2002, 279, 73-87. [CrossRef]

65. Terrados, J.; Duarte, C.M.; Fortes, M.D.; Borum, J.; Agawin, N.S.R.; Bach, S.; Thampanya, U.; Kamp-Nielsen, L.; Kenworthy, W.J.; Geertz-Hansen, O.; et al. Changes in Community Structure and Biomass of Seagrass Communities along Gradients of Siltation in SE Asia. Estuar. Coast. Shelf Sci. 1998, 46, 757-768. [CrossRef]

66. Japar Sidik, B.; Arshad, A.; Law, A.T. Inventory for Seagrass Beds in Malaysia; Department of Environment, Ministry of Science, Technology and Environment: Kuala Lumpur, Malaysia, 1995.

67. Japar Sidik, B.; Muta Harah, Z.; Mohd. Pauzi, A.; Madhavan, S. Halodule Species from Malaysia-Distribution and Morphological Variation. Aquat. Bot. 1999, 65, 33-45. [CrossRef]

68. Japar Sidik, B.; Mutah Harah, Z.; Kanamoto, Z.; Mohd Pauzi, A. Seagrass Communities of the Straits of Malacca. In Aquatic Resources and Environmental Studies of the Straits of Malacca: Current Research and Reviews; University Putra Malaysia: Serdang, Malaysia, 2001; pp. 81-98.

69. Mukai, H.; Aioi, K.; Lewmanomont, K.; Matsumasa, M.; Nakaoka, M.; Nojima, S.; Supanwanid, C.; Suzuki, T.; Toyohara, T. Dugong Grazing on Halophila Beds in Haad Chao Mai National Park, Trang Province, Thailand-How Many Dugongs Can Survive? In Proceedings of Grazing and Disturbance by Dugongs and Turtles on Tropical Seagrass Ecosystems; Ocean Research Institute, the University of Tokyo: Tokyo, Japan, 1999; pp. 239-254.

70. Parthasarathy, N.; Ravikumar, K.; Ramamurthy, K. Halophila Decipiens Ostenf. In Southern India. Aquat. Bot. 1988, 32, 179-185. [CrossRef]

71. Parthasarathy, N.; Ravikumar, K.; Ganesan, R.; Ramamurthy, K. Distribution of Seagrasses along the Coast of Tamil-Nadu, Sothern India. Aquat. Bot. 1991, 40, 145-153. [CrossRef]

72. Short, F.T.; Polidoro, B.; Livingstone, S.R.; Carpenter, K.E.; Bandeira, S.; Bujang, J.S.; Calumpong, H.P.; Carruthers, T.J.B.; Coles, R.G.; Dennison, W.C.; et al. Extinction Risk Assessment of the World's Seagrass Species. Biol. Conserv. 2011, 144, 1961-1971. [CrossRef] 
73. Walker, D.I.; McComb, A.J. Seagrass Degradation in Australian Coastal Waters. Mar. Pollut. Bull. 1992, 25, 191-195. [CrossRef]

74. Dennison, W.C.; Abal, E.G. Moreton Bay Study: A Scientific Basis for the Healthy Waterways Campaign; South East Qld Regional Water Quality Management Strategy Team: Brisbane, Australia, 1999.

75. Larkum, A.W.D.; West, R.J. Long-Term Changes of Seagrass Meadows in Botany-Bay, Australia. Aquat. Bot. 1990, 37, 55-70. [CrossRef]

76. Kirkman, H.; Kendrick, G.A. Ecological Significance and Commercial Harvesting of Drifting and Beach-Cast Macro-Algae and Seagrasses in Australia: A Review. J. Appl. Phycol. 1997, 9, 311-326. [CrossRef]

77. Wells, F.E.; Walker, D.I.; Hutchings, P.A. Seagrass, Sediment and Infauna-A Comparison of Posidonia Australis, Posidonia Sinuosa and Amphibolis Antarctica in Princess Royal Harbour, South-Western Australia. III. Consequences of Seagrass Loss; Flora Fauna Albany Area: Perth, Australia, 1991; pp. 635-640.

78. Silberstein, K.; Chiffings, A.W.; McComb, A.J. The Loss of Seagrass in Cockburn Sound, Western Australia. 3. The Effect of Epiphytes on Productivity of Posidonia australis Hook F. Aquat. Bot. 1986, 24, 355-371. [CrossRef]

79. Cambridge, M.L.; Chiffings, A.W.; Brittan, C.; Moore, L.; McComb, A.J. The Loss of Segrass in Cockburn Sound Western Australia 2. Possible Causes of Seagrass Decline. Aquat. Bot. 1986, 24, 269-285. [CrossRef]

80. Hall, M.O.; Durako, M.J.; Fourqurean, J.W.; Zieman, J.C. Decadal Changes in Seagrass Distribution and Abundance in Florida Bay. Estuaries 1999, 22, 445-459. [CrossRef]

81. Borum, J.; Pedersen, O.; Greve, T.M.; Frankovich, T.A.; Zieman, J.C.; Fourqurean, J.W.; Madden, C.J. The Potential Role of Plant Oxygen and Sulphide Dynamics in Die-off Events of the Tropical Seagrass, Thalassia testudinum. J. Ecol. 2005, 93, 148-158. [CrossRef]

82. Thayer, G.W.; Bjorndal, K.A.; Ogden, J.C.; Williams, S.L.; Zieman, J.C. Role of Larger Herbivores in Seagrass Communities. Estuaries 1984, 7, 351-376. [CrossRef]

83. Short, F.T.; Wyllie-Echeverria, S. Natural and Human-Induced Disturbance of Seagrasses. Environ. Conserv. 1996, 23, 17-27. [CrossRef]

84. Wyllie-Echeverria, S.; Arzel, P.; Cox, P.A. Seagrass Conservation: Lessons from Ethnobotany. Pac. Conserv. Biol. 1999, 5, 329-335. [CrossRef]

85. Lathrop, R.G.; Styles, R.M.; Seitzinger, S.P.; Bognar, J.A. Use of GIS Mapping and Modeling Approaches to Examine the Spatial Distribution of Seagrasses in Barnegat Bay, New Jersey. Estuaries 2001, 24, 904-916. [CrossRef]

86. Renn, C.E. Wasting Disease of Zostera in American Waters. Nature 1934, 134, 416. [CrossRef]

87. Tutin, T.G. The Autecology of Zostera marina in Relation to Its Wasting Disease. New Phytol. 1938, 37, 50-71. [CrossRef]

88. Sargent, F.J.; Leary, T.J.; Crewz, D.W.; Kruer, C.R. Scarring of Florida's Seagrasses: Assessment and Management Options. In Florida Marine Research Institute Technical Publication; Florida Marine Research Institute: St. Petersburg, FL, USA, 1995.

89. Eleuterius, L.M. The Distribution of Certain Submerged Plants in Mississippi Sound and Adjacent Waters; Gulf Coast Research Lab: Ocean Springs, MS, USA, 1973; pp. 191-197.

90. Sullivan, M.J. Epiphytic Diatoms of Three Seagrass Species in Mississippi Sound. Bull. Mar. Sci. 1979, 29, 459-464.

91. Ralph, P.J.; Short, F.T. Impact of the Wasting Disease Pathogen, Labyrinthula zosterae, on the Photobiology of Eelgrass Zostera marina. Mar. Ecol. Prog. Ser. 2002, 226, 265-271. [CrossRef]

92. Hauxwell, J.; Cebrián, J.; Furlong, C.; Valiela, I. Macroalgal Canopies Contribute to Eelgrass (Zostera marina) Decline in Temperate Estuarine Ecosystems. Ecology 2001, 82, 1007-1022. [CrossRef]

93. Phillips, R.C. The Seagrass Ecosystem and Resources in Latin America. In Coastal Plant Communities of Latin America; Seeliger, U., Ed.; Academic Press: San Diego, CA, USA, 1992; pp. 259-267.

94. Seeliger, U.; Odebrecht, C.; Castello, J.P. Subtropical Convergence Environments; Springer: Berlin, Germany, 1997.

95. Oliveira, E.C.; Pirani, J.R.; Giulietti, A.M. The Brazilian Seagrasses. Aquat. Bot. 1983, 16, 251-267. [CrossRef]

96. Blegvad, H. An Epidemic Disease of the Eelgrass (Zostera marina L.); Report from Danish Biological Station: Copenhagen, Denmark, 1935; Volume 39.

97. Nordheim, H.; von Boedeker, D. Red List of Marine and Coastal Biotopes and Biotope Complexes of the Baltic Sea, Belt Sea and Kattegat. In Baltic Sea Environment Proceedings; HELCOM: Helsinki, Finland, 1998.

98. Rasmussen, E. Systematics and Ecology of the Isefjord Marine Fauna (Denmark). Ophelia 1973, 11, 1-507. [CrossRef] 
99. Baden, S.; Gullstrom, M.; Lunden, B.; Pihl, L.; Rosenberg, R. Vanishing Seagrass (Zostera marina, L.) in Swedish Coastal Waters. Ambio 2003, 32, 374-377. [CrossRef] [PubMed]

100. Holmer, M.; Bondgaard, E.J. Photosynthetic and Growth Response of Eelgrass to Low Oxygen and High Sulfide Concentrations during Hypoxic Events. Aquat. Bot. 2001, 70, 29-38. [CrossRef]

101. Whelan, P.W.; Cullinane, J.P. The Occurrence of “wasting Disease" of Zostera in Ireland in the 1930's. Aquat. Bot. 1987, 27, 285-289. [CrossRef]

102. Jonge, V.N.; De Jong, D.J. Role of Tide, Light and Fisheries in the Decline of Zostera marina L. in the Dutch Wadden Sea; Netherlands Institute for Sea Research (NIOZ) Publication Series: Ameland, The Netherlands, 1992; Volume 20, pp. 161-176.

103. Frederiksen, M.; Krause-Jensen, D.; Holmer, M.; Laursen, J.S. Long-Term Changes in Area Distribution of Eelgrass (Zostera marina) in Danish Coastal Waters. Aquat. Bot. 2004, 78, 167-181. [CrossRef]

104. Komatsu, T.; Meinesz, A.; Buckles, D. Temperature and Light Responses of Alga Caulerpa taxifolia Introduced into the Mediterranean Sea. Mar. Ecol. Prog. Ser. 1997, 146, 145-153. [CrossRef]

105. De Falco, G.; Baroli, M.; Murru, E.; Piergallini, G.; Cancemi, G. Sediment Analysis Evidences Two Different Depositional Phenomena Influencing Seagrass Distribution in the Gulf of Oristano (Sardinia, Western Mediterranean). J. Coast. Res. 2006, 22, 1043-1050. [CrossRef]

106. Cavazza, W.; Immordino, F.; Moretti, L.; Peirano, A.; Pironi, A.; Ruggiero, F. Sedimentological Parameters and Seagrasses Distributions as Indicators of Anthropogenic Coastal Degradation at Monterosso Bay (Ligurian Sea, NW Italy). J. Coast. Res. 2000, 16, 295-305.

107. Dahl, M.; Deyanova, D.; Lyimo, L.D.; Naslund, J.; Samuelsson, G.S.; Mtolera, M.S.P.; Bjork, M.; Gullstrom, M. Effects of Shading and Simulated Grazing on Carbon Sequestration in a Tropical Seagrass Meadow. J. Ecol. 2016, 104, 654-664. [CrossRef]

108. Jones, B.L.; Unsworth, R.K.F. The Perilous State of Seagrass in the British Isles. R. Soc. Open Sci. 2016, 3, 150596. [CrossRef] [PubMed]

109. Bergmann, N.; Winters, G.; Rauch, G.; Eizaguirre, C.; Gu, J.; Nelle, P.; Fricke, B.; Reusch, T.B.H. Population-Specificity of Heat Stress Gene Induction in Northern and Southern Eelgrass Zostera marina Populations under Simulated Global Warming. Mol. Ecol. 2010, 19, 2870-2883. [CrossRef] [PubMed]

110. Connell, S.D.; Fernandes, M.; Burnell, O.W.; Doubleday, Z.A.; Griffin, K.J.; Irving, A.D.; Leung, J.Y.S.; Owen, S.; Russell, B.D.; Falkenberg, L.J. Testing for Thresholds of Ecosystem Collapse in Seagrass Meadows. Conserv. Biol. 2017, 31, 1196-1201. [CrossRef] [PubMed]

111. Duarte, C.M. Submerged Aquatic Vegetation in Relation to Different Nutrient Regimes. Ophelia 1995, 41, 87-112. [CrossRef]

112. Mabrouk, L.; Hamza, A.; Ben Brahim, M.; Bradai, M.N. Variability in the Structure of Epiphyte Assemblages on Leaves and Rhizomes of Posidonia oceanica in Relation to Human Disturbances in a Seagrass Meadow off Tunisia. Aquat. Bot. 2013, 108, 33-40. [CrossRef]

113. Burkholder, J.M.; Tomasko, D.A.; Touchette, B.W. Seagrasses and Eutrophication. J. Exp. Mar. Biol. Ecol. 2007, 350, 46-72. [CrossRef]

114. Corbett, D.R.; Chanton, J.; Burnett, W.; Dillon, K.; Rutkowski, C.; Fourqurean, J.W. Patterns of Groundwater Discharge into Florida Bay. Limnol. Oceanogr. 1999, 44, 1045-1055. [CrossRef]

115. Jørgensen, B. Ecology of the Bacteria of the Sulphur Cycle with Special Reference to Anoxic-Oxic Interface Environments. Philos. Trans. R. Soc. Lond. B Biol. Sci. 1982, 298, 543-561. [CrossRef] [PubMed]

116. Carlson, P.R.; Yarbro, L.A.; Barber, T.R. Relationship of Sediment Sulfide to Mortality of Thalassia testudinum in Florida Bay. Bull. Mar. Sci. 1994, 54, 733-746.

117. Durako, M.J.; Kuss, K.M. Effects of Labyrinthula Infection on the Photosynthetic Capacity of Thalassia testudinum. Bull. Mar. Sci. 1994, 54, 727-732.

118. Fourqurean, J.W.; Powell, G.V.N.; Kenworthy, W.J.; Zieman, J.C. The Effects of Long-Term Manipulation of Nutrient Supply on Competition Between the Seagrasses Thalassia testudinum and Halodule wrightii in Florida Bay. Oikos 1995, 72, 349-358. [CrossRef]

119. Davis, B.C.; Fourqurean, J.W. Competition between the Tropical Alga, Halimeda incrassata, and the Seagrass, Thalassia testudinum. Aquat. Bot. 2001, 71, 217-232. [CrossRef]

120. Muehlstein, L.K. The Host-Pathogen Interaction in the Wasting Disease of Eelgrass, Zostera marina. Can. J. Bot. Can. Bot. 1992, 70, 2081-2088. [CrossRef] 
121. Short, F.T.; Ibelings, B.W.; Den Hartog, C. Comparison of a Current Eelgrass Disease to the Wasting Disease in the 1930s; Elsevier: Amsterdam, The Netherlands, 1988; pp. 295-304.

122. Peterson, B.J.; Rose, C.D.; Rutten, L.M.; Fourqurean, J.W. Disturbance and Recovery Following Catastrophic Grazing: Studies of a Successional Chronosequence in a Seagrass Bed. Oikos 2002, 97, 361-370. [CrossRef]

123. Fourqurean, J.W.; Rutten, L.M. The Impact of Hurricane Georges on Soft-Bottom, Back Reef Communities: Site- and Species-Specific Effects in South Florida Seagrass Beds. Bull. Mar. Sci. 2004, 75, $239-257$.

124. Bourque, A.S.; Vega-Thurber, R.; Fourqurean, J.W. Microbial Community Structure and Dynamics in Restored Subtropical Seagrass Sediments. Aquat. Microb. Ecol. 2015, 74, 43-57. [CrossRef]

125. Margulis, L. Symbiogenesis and Symbionticism. In Symbiosis as a Source of Evolutionary Innovation; Margulis, L., Fester, R., Eds.; Cambridge MIT Press: Cambridge, MA, USA, 1991.

126. Douglas, A.E.; Werren, J.H. Holes in the Hologenome: Why Host-Microbe Symbioses Are Not Holobionts. mBio 2016, 7, e02099-15. [CrossRef] [PubMed]

127. Theis, K.R.; Dheilly, N.M.; Klassen, J.L.; Brucker, R.M.; Baines, J.F.; Bosch, T.C.G.; Cryan, J.F.; Gilbert, S.F.; Goodnight, C.J.; Lloyd, E.A.; et al. Getting the Hologenome Concept Right: An Eco-Evolutionary Framework for Hosts and Their Microbiomes. mSystems 2016, 1, e00028-16. [CrossRef] [PubMed]

128. Rosenberg, E.; Zilber-Rosenberg, I. Microbes Drive Evolution of Animals and Plants: The Hologenome Concept. mBio 2016, 7, e01395-15. [CrossRef] [PubMed]

129. Bourne, D.G.; Morrow, K.M.; Webster, N.S. Insights into the Coral Microbiome: Underpinning the Health and Resilience of Reef Ecosystems. Annu. Rev. Microbiol. 2016, 70, 317-340. [CrossRef] [PubMed]

130. Webster, N.S.; Thomas, T. The Sponge Hologenome. mBio 2016, 7, e00135-16. [CrossRef] [PubMed]

131. Human Microbiome Project Consortium. Structure, Function and Diversity of the Healthy Human Microbiome. Nature 2012, 486, 207-214.

132. Zilber-Rosenberg, I.; Rosenberg, E. Role of Microorganisms in the Evolution of Animals and Plants: The Hologenome Theory of Evolution. FEMS Microbiol. Rev. 2008, 32, 723-735. [CrossRef] [PubMed]

133. Vandenkoornhuyse, P.; Quaiser, A.; Duhamel, M.; Le Van, A.; Dufresne, A. The Importance of the Microbiome of the Plant Holobiont. New Phytol. 2015, 206, 1196-1206. [CrossRef] [PubMed]

134. Sanchez-Cañizares, C.; Jorrin, B.; Poole, P.S.; Tkacz, A. Understanding the Holobiont: The Interdependence of Plants and Their Microbiome. Curr. Opin. Microbiol. 2017, 38, 188-196. [CrossRef] [PubMed]

135. Borowitzka, M.A.; Lavery, P.S.; van Keulen, M. Epiphytes of Seagrasses BT-Seagrasses: Biology, Ecology and Conservation; Larkum, A.W.D., Orth, R.J., Duarte, C.M., Eds.; Springer: Dordrecht, The Netherlands, 2006; pp. 441-461.

136. Devereux, R. Seagrass Rhizosphere Microbial Communities. In Interactions Between Macro-and Microorganisms in Marine Sediments; Kristensen, E., Haese, R.R., Kostka, J.E., Eds.; American Geophysical Union: Washington, DC, USA, 2005.

137. Agawin, N.S.R.; Ferriol, P.; Cryer, C.; Alcon, E.; Busquets, A.; Sintes, E.; Vidal, C.; Moyà, G. Significant Nitrogen Fixation Activity Associated with the Phyllosphere of Mediterranean Seagrass Posidonia oceanica: First Report. Mar. Ecol. Prog. Ser. 2016, 551, 53-62. [CrossRef]

138. Bagwell, C.E.; La Rocque, J.R.; Smith, G.W.; Polson, S.W.; Friez, M.J.; Longshore, J.W.; Lovell, C.R. Molecular Diversity of Diazotrophs in Oligotrophic Tropical Seagrass Bed Communities. FEMS Microbiol. Ecol. 2002, 39, 113-119. [CrossRef] [PubMed]

139. Kurilenko, V.V.; Christen, R.; Zhukova, N.V.; Kalinovskaya, N.I.; Mikhailov, V.V.; Crawford, R.J.; Ivanova, E.P. Granulosicoccus coccoides sp. nov., Isolated from Leaves of Seagrass (Zostera marina). Int. J. Syst. Evol. Microbiol. 2010, 60, 972-976. [CrossRef] [PubMed]

140. Küsel, K.; Pinkart, H.C.; Drake, H.L.; Devereux, R. Acetogenic and Sulfate-Reducing Bacteria Inhabiting the Rhizoplane and Deep Cortex Cells of the Sea Grass Halodule wrightii. Appl. Environ. Microbiol. 1999, 65, 5117-5123. [PubMed]

141. Marhaeni, B.; Radjasa, O.K.; Bengen, D.G.; Kaswadji, R.F. Screening of Bacterial Symbionts of Seagrass Enhalus sp. against Biofilm-Forming Bacteria. J. Coast. Dev. 2010, 13, 126-132.

142. Newell, S.Y. Fungi and Bacteria in or on Leaves of Eelgrass (Zostera marina L.) from Chesapeake Bay. Appl. Environ. Microbiol. 1981, 41, 1219-1224. [PubMed]

143. Nielsen, L.B.; Finster, K.; Welsh, D.T.; Donelly, A.; Herbert, R.A.; De Wit, R.; Lomstein, B.A.A. Sulphate Reduction and Nitrogen Fixation Rates Associated with Roots, Rhizomes and Sediments from Zostera noltii and Spartina maritima Meadows. Environ. Microbiol. 2001, 3, 63-71. [CrossRef] [PubMed] 
144. Blaabjerg, V.; Finster, K. Sulphate Reduction Associated with Roots and Rhizomes of the Marine Macrophyte Zostera marina. Aquat. Microb. Ecol. 1998, 15, 311-314. [CrossRef]

145. Blaabjerg, V.; Mouritsen, K.N.; Finster, K. Diel Cycles of Sulphate Reduction Rates in Sediments of a Zostera marina Bed (Denmark). Aquat. Microb. Ecol. 1998, 15, 97-102. [CrossRef]

146. Boon, P.I.; Moriarty, D.J.W.; Saffigna, P.G. Rates of Ammonium Turnover and the Role of Amino-Acid Deamination in Seagrass (Zostera capricorni) Beds of Moreton Bay, Australia. Mar. Biol. 1986, 91, 259-268. [CrossRef]

147. Boschker, H.T.S.; Wielemaker, A.; Schaub, B.E.M.; Holmer, M. Limited Coupling of Macrophyte Production and Bacterial Carbon Cycling in the Sediments of Zostera spp. Meadows. Mar. Ecol. Prog. Ser. 2000, 203, 181-189. [CrossRef]

148. Caffrey, J.; Kemp, W. Nitrogen Cycling in Sediments with Estuarine Populations of Potamogeton perfoliatus and Zostera marina. Mar. Ecol. Prog. Ser. 1990, 66, 147-160. [CrossRef]

149. Capone, D.G.; Taylor, B.F. $\mathrm{N}_{2}$ Fixation in the Rhizosphere of Thalassia testudinum. Can. J. Microbiol. 1980, 26, 998-1005. [CrossRef] [PubMed]

150. Frederiksen, M.S.; Glud, R.N. Oxygen Dynamics in the Rhizosphere of Zostera marina: A Two-Dimensional Planar Optode Study. Limnol. Oceanogr. 2006, 51, 1072-1083. [CrossRef]

151. Holmer, M.; Andersen, F.O.; Nielsen, S.L.; Boschker, H.T.S. The Importance of Mineralization Based on Sulfate Reduction for Nutrient Regeneration in Tropical Seagrass Sediments. Aquat. Bot. 2001, 71, 1-17. [CrossRef]

152. Holmer, M.; Duarte, C.M.; Boschker, H.T.S.; Barrón, C. Carbon Cycling and Bacterial Carbon Sources in Pristine and Impacted Mediterranean Seagrass Sediments. Aquat. Microb. Ecol. 2004, 36, 227-237. [CrossRef]

153. Isaksen, M.F.; Finster, K. Sulphate Reduction in the Root Zone of the Seagrass Zostera noltii on the Intertidal Flats of a Coastal Lagoon (Arcachon, France). Mar. Ecol. Prog. Ser. 1996, 137, 187-194. [CrossRef]

154. Jones, W.B.; Cifuentes, L.A.; Kaldy, J.E. Stable Carbon Isotope Evidence for Coupling between Sedimentary Bacteria and Seagrasses in a Sub-Tropical Lagoon. Mar. Ecol. Prog. Ser. 2003, 255, 15-25. [CrossRef]

155. Kim, B.; Choi, A.; Lee, K.S.; Kang, C.K.; Hyun, J.H. Sulfate Reduction and Sulfur Cycles at Two Seagrass Beds Inhabited by Cold Affinity Zostera Marina and Warm Affinity Halophila nipponica in Temperate Coastal Waters. Estuar. Coasts 2017, 40, 1346-1357. [CrossRef]

156. Kirchman, D.; Mazzella, L.; Alberte, R.; Mitchell, R. Epiphytic Bacterial Production on Zostera marina. Mar. Ecol. Prog. Ser. 1984, 15, 117-123. [CrossRef]

157. Koepfler, E.T.; Benner, R.; Montagna, P.A. Variability of Dissolved Organic Carbon in Sediments of a Seagrass Bed and an Unvegetated Area within an Estuary in Southern Texas. Estuaries 1993, 16, 391-404. [CrossRef]

158. Lee, K.S.; Dunton, K.H. Diurnal Changes in Pore Water Sulfide Concentrations in the Seagrass Thalassia testudinum Beds: The Effects of Seagrasses on Sulfide Dynamics. J. Exp. Mar. Biol. Ecol. 2000, 255, 201-214. [CrossRef]

159. Lopez, N.I.; Duarte, C.M.; Vallespinos, F.; Romero, J.; Alcoverro, T. Bacterial Activity in NW Mediterranean Seagrass (Posidonia oceanica) Sediments. J. Exp. Mar. Biol. Ecol. 1995, 187, 39-49. [CrossRef]

160. McGlathery, K.J.; Risgaard-Petersen, N.; Christensen, P.B. Temporal and Spatial Variation in Nitrogen Fixation Activity in the Eelgrass Zostera marina Rhizosphere. Mar. Ecol. Prog. Ser. 1998, 168, 245-258. [CrossRef]

161. Moriarty, D.J.; Boon, P.I.; Hansen, J.A.; Hunt, W.G.; Poiner, I.R.; Pollard, P.C.; Skyring, G.W.; White, D.C. Microbial Biomass and Productivity in Seagrass Beds. Geomicrobiol. J. 1985, 4, 21-51. [CrossRef] [PubMed]

162. Moriarty, D.J.W.; Iverson, R.L.; Pollard, P.C. Exudation of Organic Carbon by the Seagrass Halodule wrightii Aschers. And Its Effect on Bacterial Growth in the Sediment. J. Exp. Mar. Biol. Ecol. 1986, 96, 115-126. [CrossRef]

163. Oremland, R.S.; Taylor, B.F. Diurnal Fluctuations of $\mathrm{O}_{2}, \mathrm{~N}_{2}$, and $\mathrm{CH}_{4}$ in the Rhizosphere of Thalassia testudinum. Limnol. Oceanogr. 1977, 22, 566-571. [CrossRef]

164. Patriquin, D.; Knowles, R. Nitrogen Fixation in the Rhizosphere of Marine Angiosperms. Mar. Biol. 1972, 16, 49-58. [CrossRef]

165. Penhale, P.A.; Smith, W.O. Excretion of Dissolved Organic Carbon by Eelgrass (Zostera marina) and Its Epiphytes. Limnol. Oceanogr. 1977, 22, 400-407. [CrossRef]

166. Sand-Jensen, K.; Pedersen, O.; Binzer, T.; Borum, J. Contrasting Oxygen Dynamics in the Freshwater Isoetid Lobelia Dortmanna and the Marine Seagrass Zostera marina. Ann. Bot. 2005, 96, 613-623. [CrossRef] [PubMed] 
167. Smith, G.W.; Hayasaka, S.S.; Thayer, G.W. Ammonification of Amino Acids by the Rhizoplane Microflora of Zostera marina L. and Halodule wrightii Aschers. Bot. Mar. 1984, 27, 23-28. [CrossRef]

168. Smith, R.D.; Dennison, W.C.; Alberte, R.S. Role of Seagrass Photosynthesis in Root Aerobic Processes. Plant Physiol. 1984, 74, 1055-1058. [CrossRef] [PubMed]

169. Törnblom, E.; Søndergaard, M. Seasonal Dynamics of Bacterial Biomass and Production on Eelgrass Zostera marina Leaves. Mar. Ecol. Prog. Ser. 1999, 179, 231-240. [CrossRef]

170. Welsh, D.T.; Bourgues, S.; Dewit, R.; Herbert, R.A. Seasonal Variation in Rates of Heterotrophic Nitrogen Fixation (Acetylene Reduction) in Zostera noltii Meadows and Uncolonised Sediments of the Bassin Darcachon, South-West France. Hydrobiologia 1996, 329, 161-174. [CrossRef]

171. Wetzel, R.G.; Penhale, P.A. Transport of Carbon and Excretion of Dissolved Organic Carbon by Leaves and Roots/rhizomes in Seagrasses and Their Epiphytes. Aquat. Bot. 1979, 6, 149-158. [CrossRef]

172. Williams, C.J.; Jaffé, R.; Anderson, W.T.; Jochem, F.J. Importance of Seagrass as a Carbon Source for Heterotrophic Bacteria in a Subtropical Estuary (Florida Bay). Estuar. Coast. Shelf Sci. 2009, 85, 507-514. [CrossRef]

173. Bengtsson, M.M.; Bühler, A.; Brauer, A.; Dahlke, S.; Schubert, H.; Blindow, I. Eelgrass Leaf Surface Microbiomes Are Locally Variable and Highly Correlated with Epibiotic Eukaryotes. Front. Microbiol. 2017, 8, 1-11. [CrossRef] [PubMed]

174. Cifuentes, A.; Antón, J.; Benlloch, S.; Donnelly, A.; Herbert, R.A.; Rodríguez-Valera, F. Prokaryotic Diversity in Zostera noltii -Colonized Marine Sediments. Appl. Environ. Microbiol. 2000, 66, 1715-1719. [CrossRef] [PubMed]

175. Crump, B.C.; Koch, E.W. Attached Bacterial Populations Shared by Four Species of Aquatic Angiosperms. Appl. Environ. Microbiol. 2008, 74, 5948-5957. [CrossRef] [PubMed]

176. Cúcio, C.; Engelen, A.H.; Costa, R.; Muyzer, G. Rhizosphere Microbiomes of European + Seagrasses Are Selected by the Plant, but Are Not Species Specific. Front. Microbiol. 2016, 7, 440. [CrossRef] [PubMed]

177. Donnelly, P.; Herbert, R. Bacterial Interactions in the Rhizosphere of Seagrass Communities in Shallow Coastal Lagoons. J. Appl. Microbiol. 1998, 85 (Suppl. 1), 151S-160S. [CrossRef] [PubMed]

178. Ettinger, C.L.; Voerman, S.E.; Lang, J.M.; Stachowicz, J.J.; Eisen, J.A. Microbial Communities in Sediment from Zostera marina Patches, but Not the Z. marina Leaf or Root Microbiomes, Vary in Relation to Distance from Patch Edge. Peer] 2017, 5, e3246. [CrossRef] [PubMed]

179. Fahimipour, A.K.; Kardish, M.R.; Lang, J.M.; Green, J.L.; Eisen, J.A.; Stachowicz, J.J. Global-Scale Structure of the Eelgrass Microbiome. Appl. Environ. Microbiol. 2017, 83, e03391-16. [CrossRef] [PubMed]

180. Glazebrook, P.W.; Moriarty, G.; Hayward, A.C.; Macrae, I.C. Seasonal Changes in Numbers and the Location of a Particular Bacterial Strain of Alteromonas sp. in Seagrass Sediments. Microb. Ecol. 1996, 31, 1-13. [CrossRef] [PubMed]

181. Gnavi, G.; Ercole, E.; Panno, L.; Vizzini, A.; Varese, G.C. Dothideomycetes and Leotiomycetes Sterile Mycelia Isolated from the Italian Seagrass Posidonia oceanica Based on rDNA Data. Springerplus 2014, 3, 508. [CrossRef] [PubMed]

182. Green-García, A.M.; Engel, A.S. Bacterial Diversity of Siliciclastic Sediments in a Thalassia testudinum Meadow and the Implications for Lucinisca nassula Chemosymbiosis. Estuar. Coast. Shelf Sci. 2012, 112, 153-161. [CrossRef]

183. Jankowska, E.; Jankowska, K.; Włodarska-Kowalczuk, M. Seagrass Vegetation and Meiofauna Enhance the Bacterial Abundance in the Baltic Sea Sediments (Puck Bay). Environ. Sci. Pollut. Res. 2015, 22, 14372-14378. [CrossRef] [PubMed]

184. Jensen, S.I.; Kühl, M.; Priemé, A. Different Bacterial Communities Associated with the Roots and Bulk Sediment of the Seagrass Zostera marina. FEMS Microbiol. Ecol. 2007, 62, 108-117. [CrossRef] [PubMed]

185. Jiang, Y.-F.; Ling, J.; Wang, Y.-S.; Chen, B.; Zhang, Y.-Y.; Dong, J.-D. Cultivation-Dependent Analysis of the Microbial Diversity Associated with the Seagrass Meadows in Xincun Bay, South China Sea. Ecotoxicology 2015, 24, 1540-1547. [CrossRef] [PubMed]

186. Kurilenko, V.V.; Ivanova, E.P.; Mikhailov, V.V. Peculiarities of Adhesion of Epiphytic Bacteria on Leaves of the Seagrass Zostera marina and on Abiotic Surfaces. Microbiology 2007, 76, 442-445. [CrossRef]

187. Ling, J.; Zhang, Y.; Wu, M.; Wang, Y.; Dong, J.; Jiang, Y.; Yang, Q.; Zeng, S. Fungal Community Successions in Rhizosphere Sediment of Seagrasses Enhalus Acoroides under PAHs Stress. Int. J. Mol. Sci. 2015, 16, 14039-14055. [CrossRef] [PubMed] 
188. Mejia, A.Y.; Rotini, A.; Lacasella, F.; Bookman, R.; Thaller, M.C.; Shem-Tov, R.; Winters, G.; Migliore, L. Assessing the Ecological Status of Seagrasses Using Morphology, Biochemical Descriptors and Microbial Community Analyses. A Study in Halophila stipulacea (Forsk.) Aschers Meadows in the Northern Red Sea. Ecol. Indic. 2016, 60, 1150-1153. [CrossRef]

189. Nielsen, J.; Liesack, W.; Finster, K. Desulfovibrio zosterae Sp. Nov., a New Sulfate Reducer Isolated from Surface-Sterilized Roots of the Seagrass Zostera marina. Int. J. Syst. Bacteriol. 1999, 49, 859-865. [CrossRef] [PubMed]

190. Novak, R. A Study in Ultra-Ecology: Microorganisms on the Seagrass Posidonia oceanica (L.) Delile. Mar. Ecol. 1984, 5, 143-190. [CrossRef]

191. Panno, L.; Bruno, M.; Voyron, S.; Anastasi, A.; Gnavi, G.; Miserere, L.; Varese, G.C. Diversity, Ecological Role and Potential Biotechnological Applications of Marine Fungi Associated to the Seagrass Posidonia oceanica. New Biotechnol. 2013, 30, 686-694. [CrossRef] [PubMed]

192. Sun, F.; Zhang, X.; Zhang, Q.; Liu, F.; Zhang, J.; Gong, J. Seagrass (Zostera marina) Colonization Promotes the Accumulation of Diazotrophic Bacteria and Alters the Relative Abundances of Specific Bacterial Lineages Involved in Benthic Carbon and Sulfur Cycling. Appl. Environ. Microbiol. 2015, 81, 6901-6914. [CrossRef] [PubMed]

193. Weidner, S.; Arnold, W.; Pühler, A. Diversity of Uncultured Microorganisms Associated with the Seagrass Halophila stipulacea Estimated by Restriction Fragment Length Polymorphism Analysis of PCR-Amplified 16s rRNA Genes. Appl. Environ. Microbiol. 1996, 62, 766-771. [PubMed]

194. Moriarty, D.J.W.; Pollard, P.C. Diel Variation of Bacterial Productivity in Seagrass (Zostera capricorni) Beds Measured by Rate of Thymidine Incorporation into DNA. Mar. Biol. 1982, 72, 165-173. [CrossRef]

195. O’Donohue, M.J.; Moriarty, D.J.; Rae, I.C. Nitrogen Fixation in Sediments and the Rhizosphere of the Seagrass Zostera capricorni. Microb. Ecol. 1991, 22, 53-64. [CrossRef] [PubMed]

196. Welsh, D. Nitrogen Fixation in Seagrass Meadows: Regulation, Plant \pm Bacteria Interactions and Significance to Primary Productivity. Ecol. Lett. 2000, 3, 58-71. [CrossRef]

197. Cole, L.W.; McGlathery, K.J. Nitrogen Fixation in Restored Eelgrass Meadows. Mar. Ecol. Prog. Ser. 2012, 448, 235-246. [CrossRef]

198. Smith, A.C.; Kostka, J.E.; Devereux, R.; Yates, D.F. Seasonal Composition and Activity of Sulfate-Reducing Prokaryotic Communities in Seagrass Bed Sediments. Aquat. Microb. Ecol. 2004, 37, 183-195. [CrossRef]

199. Pollard, P.C.; Moriarty, D.J.W. Organic Carbon Decomposition, Primary and Bacterial Productivity, and Sulphate Reduction, in Tropical Seagrass Beds of the Gulf of Carpentaria, Australia. Mar. Ecol. Prog. Ser. 1991, 69, 149-159. [CrossRef]

200. Blackburn, T.H.; Nedwell, D.B.; Wiebe, W.J. Active Mineral Cycling in a Jamaican Seagrass Sediment. Mar. Ecol. Prog. Ser. 1994, 110, 233-239. [CrossRef]

201. Moriarty, D.J.W.; Roberts, D.G.; Pollard, P.C. Primary and Bacterial Productivity of Tropical Seagrass Communities in the Gulf of Carpentaria, Australia. Mar. Ecol. Prog. Ser. 1990, 61, 145-157. [CrossRef]

202. Koch, M.S.; Erskine, J.M. Sulfide as a Phytotoxin to the Tropical Seagrass Thalassia testudinum: Interactions with Light, Salinity and Temperature. J. Exp. Mar. Biol. Ecol. 2001, 266, 81-95. [CrossRef]

203. Krause-Jensen, D.; Carstensen, J.; Nielsen, S.L.; Dalsgaard, T.; Christensen, P.B.; Fossing, H.; Rasmussen, M.B. Sea Bottom Characteristics Affect Depth Limits of Eelgrass Zostera marina. Mar. Ecol. Prog. Ser. 2011, 425, 91-102. [CrossRef]

204. Brodersen, K.E.; Nielsen, D.A.; Ralph, P.J.; Kuhl, M. Oxic Microshield and Local pH Enhancement Protects Zostera muelleri from Sediment Derived Hydrogen Sulphide. New Phytol. 2015, 205, 1264-1276. [CrossRef] [PubMed]

205. Hasler-Sheetal, H.; Holmer, M. Sulfide Intrusion and Detoxification in the Seagrass Zostera marina. PLoS ONE 2015, 10, e0129136. [CrossRef] [PubMed]

206. Joshi, M.M.; Hollis, J.P. Interaction of Beggiatoa and Rice Plant: Detoxification of Hydrogen Sulfide in the Rice Rhizosphere. Science 1977, 195, 179-180. [CrossRef] [PubMed]

207. Smith, R.D.; Pregnall, A.M.; Alberte, R.S. Effects of Anaerobiosis on Root Metabolism of Zostera marina (Eelgrass): Implications for Survival in Reducing Sediments. Mar. Biol. 1988, 98, 131-141. [CrossRef]

208. Ross, C.; Puglisi, M.P.; Paul, V.J. Antifungal Defenses of Seagrasses from the Indian River Lagoon, Florida. Aquat. Bot. 2008, 88, 134-141. [CrossRef] 
209. Herlemann, D.P.R.; Labrenz, M.; Jurgens, K.; Bertilsson, S.; Waniek, J.J.; Andersson, A.F. Transitions in Bacterial Communities along the $2000 \mathrm{~km}$ Salinity Gradient of the Baltic Sea. ISME J. 2011, 5, 1571-1579. [CrossRef] [PubMed]

210. Andersson, A.F.; Riemann, L.; Bertilsson, S. Pyrosequencing Reveals Contrasting Seasonal Dynamics of Taxa within Baltic Sea Bacterioplankton Communities. ISME J. 2010, 4, 171-181. [CrossRef] [PubMed]

211. Fernández-Gómez, B.; Richter, M.; Schüler, M.; Pinhassi, J.; Acinas, S.G.; González, J.M.; Pedrós-Alió, C. Ecology of Marine Bacteroidetes: A Comparative Genomics Approach. ISME J. 2013, 7, 1026-1037. [CrossRef] [PubMed]

212. Roth-Schulze, A.J.; Zozaya-Valdés, E.; Steinberg, P.D.; Thomas, T. Partitioning of Functional and Taxonomic Diversity in Surface-Associated Microbial Communities. Environ. Microbiol. 2016, 18, 4391-4402. [CrossRef] [PubMed]

213. Bourque, A.S.; Kenworthy, W.J.; Fourqurean, J.W. Impacts of Physical Disturbance on Ecosystem Structure in Subtropical Seagrass Meadows. Mar. Ecol. Prog. Ser. 2015, 540, 27-41. [CrossRef]

214. Sand-Jensen, K.; Prahl, C.; Stokholm, H. Oxygen Release from Roots of Submerged Aquatic Macrophytes. Oikos 1982, 38, 349-354. [CrossRef]

215. Sakayaroj, J.; Preedanon, S.; Supaphon, O.; Jones, E.B.G.; Phongpaichit, S. Phylogenetic Diversity of Endophyte Assemblages Associated with the Tropical Seagrass Enhalus Acoroides in Thailand. Fungal Divers. 2010, 42, 27-45. [CrossRef]

(C) 2017 by the authors. Licensee MDPI, Basel, Switzerland. This article is an open access article distributed under the terms and conditions of the Creative Commons Attribution (CC BY) license (http://creativecommons.org/licenses/by/4.0/). 